\title{
6. THE OCEAN SUB-BOTTOM SEISMOMETER SYSTEM INSTALLED IN DEEP SEA DRILLING PROJECT HOLE 581C, LEG 88: A TECHNICAL REVIEW ${ }^{1}$
}

\author{
David A. Byrne, David Harris, Fred K. Duennebier, and Robert Cessaro, Hawaii Institute of Geophysics ${ }^{2}$
}

\begin{abstract}
A permanent Ocean Sub-bottom Seismometer (OSS IV) designed and built by the Hawaii Institute of Geophysics was successfully installed in DSDP Hole 581C during Leg 88. The system consists of a borehole package, electromechanical cable, recorder package, recovery rope, and buoy. The borehole package contains vertical and horizontal geophones, tilt meters, and a temperature sensor. Signals from these sensors are multiplexed, digitized, and telemetered through the electromechanical cable to the recorder package near the ocean bottom, approximately $4 \mathrm{~km}$ from the borehole. Data are recorded continuously for up to two months on magnetic tape cassettes. The digital data are also monitored during installation and during servicing of the recorder package, which may be performed with a midsized oceanographic ship (>50 m) at any time after the installation.

Data in digital format from the OSS IV installation were recorded during installation in September, 1982, and the recorder package was first serviced in May 1983. Data continuously recorded for 65 days were recovered from the first recorder package. A second recorder package was installed in May 1983 and is presently awaiting funding for servicing.
\end{abstract}

\section{INTRODUCTION}

The Hawaii Institute of Geophysics (HIG) began developing the Ocean Sub-bottom Seismometer system (OSS) in early 1978 (Aubouin, von Huene, et al., 1979; Lewis, Robinson, et al., 1979; Duennebier and Blackinton, 1980, 1983), and to date we have attempted four installations (Fig. 1). Between OSS II and OSS III the system was significantly redesigned. This chapter describes the present OSS system and discusses possible improvements. The design goals for this system were high data return, simplicity, and low cost. To reach them, we used as much existing technology as possible (such as D-cells for power, the existing Glomar Challenger logging cable, and the HIG Ocean Bottom Seismometer (OBS) analog tape decks). For simplicity, we strove for minimum impact on the drilling operation and schedule (for example, by deploying through the drill pipe in a single-bit hole). In retrospect, these goals were achieved although more time and money for testing and analyzing the system would have been well spent.

\section{GENERAL DESCRIPTION OF THE SYSTEM}

The OSS system is a deep-ocean, long-term, borehole seismic recording system (Fig. 2), consisting of a borehole sensor package (tool), electromechanical cable, recorder package, and recovery systems. The tool was designed to be installed at the bottom of boreholes drilled by the Glomar Challenger and contains three orthogonal sets of $4.5-\mathrm{Hz}$ geophones, two orthogonal tilt meters, and a temperature sensor. Signals from these sensors are multiplexed, digitized (with a floating-point tech-

\footnotetext{
${ }^{1}$ Duennebier, F. K., Stephen, R., Gettrust, J. F., et al., Init. Repts. DSDP, 88: Washington (U.S. Govt. Printing Office).

2 Address: Hawaii Institute of Geophysics, University of Hawaii at Manoa, Honolulu, Hawaii 96822
}

nique), and telemetered through approximately $10 \mathrm{~km}$ of electromechanical cable to a recorder package near the ocean bottom. Electrical power for the tool is supplied from the recorder package. The digitized seismic signals are demultiplexed, converted back to analog through an automatic gain control (AGC) circuit, and recorded along with a time code on magnetic tape cassettes in the recorder package. The recorder package can record data continuously for up to two months. The recorder package is connected to the recovery buoy by $8 \mathrm{~km}$ of floating polypropylene rope, $3.2 \mathrm{~cm}$ in diameter. The anchor on the recovery buoy is released by activating either of two acoustical command releases.

The recovery ship may be any typical research vessel more than $50 \mathrm{~m}$ in length, preferably with a large Aframe. The recovery rope and recorder package are hauled aboard the recovery ship with a special traction winch. The recorder package is serviced, real-time experiments are conducted, and the recorder package is reinstalled. During real-time recording, the data acquisition rate can be increased by a factor of 2 .

\section{MECHANICAL SYSTEM}

The OSS system is divided into three mechanical subsystems: (1) the tool and electromechanical cable, (2) the recorder package, and (3) the recovery systems.

\section{The Tool (borehole package)}

The tool (borehole package) (Fig. 3) is a modified density-logging tool manufactured by Gearhart Industries. It is $2.5 \mathrm{~m}$ long and $7 \mathrm{~cm}$ in diameter. It was modified to allow the pad to extend farther, and the arm on the opposite side of the tool was removed, thus improving the seismic coupling of the tool to the borehole (Fig. 4).

The tool is divided into three parts: upper pressure case, body, and pad. The upper pressure case has an inside diameter of $6 \mathrm{~cm}$ and withstands pressure to a depth 


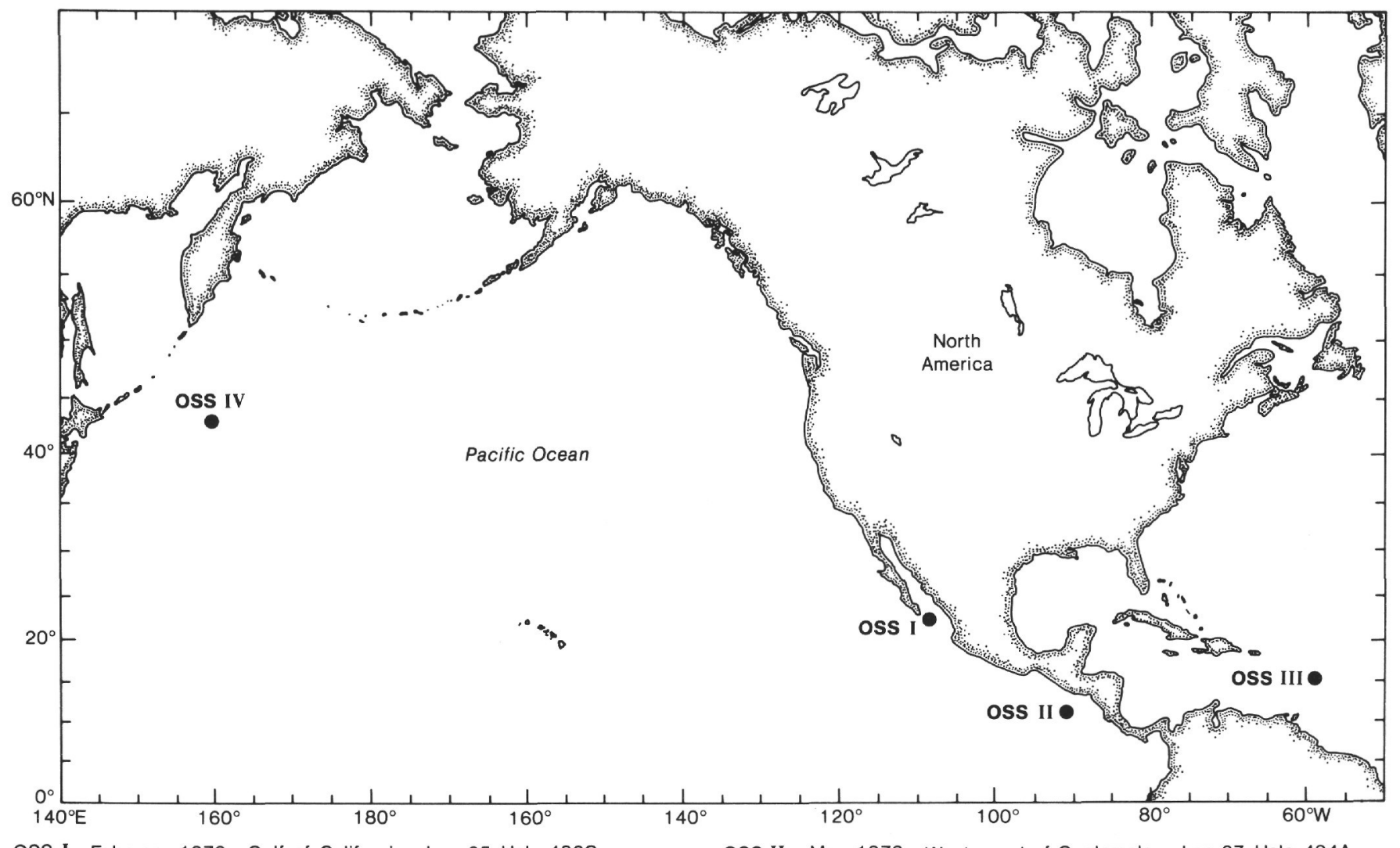

OSS I February 1979 Gulf of California Leg 65, Hole 482C

Only real-time data recovered. No long-term data because of mechanical damage to the tool during installation and high temperature in the borehole. Tool still operating after 42 days in the hole. Temperature of $150^{\circ} \mathrm{C}$ recorded when tool pulled from hole.

OSS III February 1981 Barbados Ridge Leg 78, Hole 541

No data because of telemetering noise from major redesign. Recorder package not installed.
OSS II May 1979 West coast of Guatemala Leg 67, Hole 494A

Four months of continuous data collected. Seismic data degraded because of DC offsets. Tool still operating after 2 nd recovery with more than $1 \mathrm{yr}$. in hole. Tool lost when cable parted during attempt to pull tool from hole.

OSS IV September 1982 East of Kuril Is. Leg 88, Hole 581C

Two months of continuous data and 3 days of real-time data recovered Tool still installed and $100 \%$ operational with 65 days of data waiting for recovery.

Figure 1. Ocean Sub-bottom Seismometer (OSS) installations I through IV.

of $6 \mathrm{~km}$. The cablehead (electromechanical connector) is mounted to the top of the pressure case, and the lower end of the pressure case is attached to the body. The electronics card cage with the horizontal geophones, tilt meters, and temperature sensor are housed in this pressure case (Fig. 5A and 5B). The upper section of the card cage contains four printed circuit cards and the three geophone preamplifier cards. The four horizontal geophones are located below these cards. The tilt meters, mounted on PC cards with their preamplifiers, are in the lowest section of the card cage and are positioned orthogonally in line with the horizontal geophones. The tilt meter section of the card cage is encapsulated with a polyurethane compound to contain the corrosive sensor fluid in the event that the glass tilt meters were to break and to inhibit breaking caused by mechanical shock. The temperature sensor is thermally coupled to the lower end of the pressure case. The entire card cage has a mass of $3 \mathrm{~kg}$, is $68 \mathrm{~cm}$ long, and is held in place by two indexing pins and a electrical connector (DE-9). Also housed in this section is the direct current (DC) drive motor, which retracts and extends the pad.
The tool body contains the pad extension hardware. When retracted, the pad is housed in a cradle in the body, but it can be extended to lock the tool in place in any hole with a diameter between 8 and $35 \mathrm{~cm}$. At the bottom of the tool is the bullnose. It has a single electrical conductor from the upper pressure case but is unused in the OSS.

The extendable pad contains a vertical geophone stack (Figure 5C). Two electrical conductors connect the pad to the upper pressure case. The nine geophones are connected in series to increase vertical signal-to-noise ratio.

The electromechanical cablehead is connected to the top of the tool. The cable is the standard cable routinely used aboard the Challenger, a seven-conductor, doublearmored, torque balanced cable $1.2 \mathrm{~cm}$ in diameter. The Gearhart Industries cablehead is filled with a polyurethane compound to increase the survival time of a permanent emplacement.

\section{The Recorder Package}

The recorder package consists of two pressure cases, a strain-transmitting assembly rod, and two electronic 


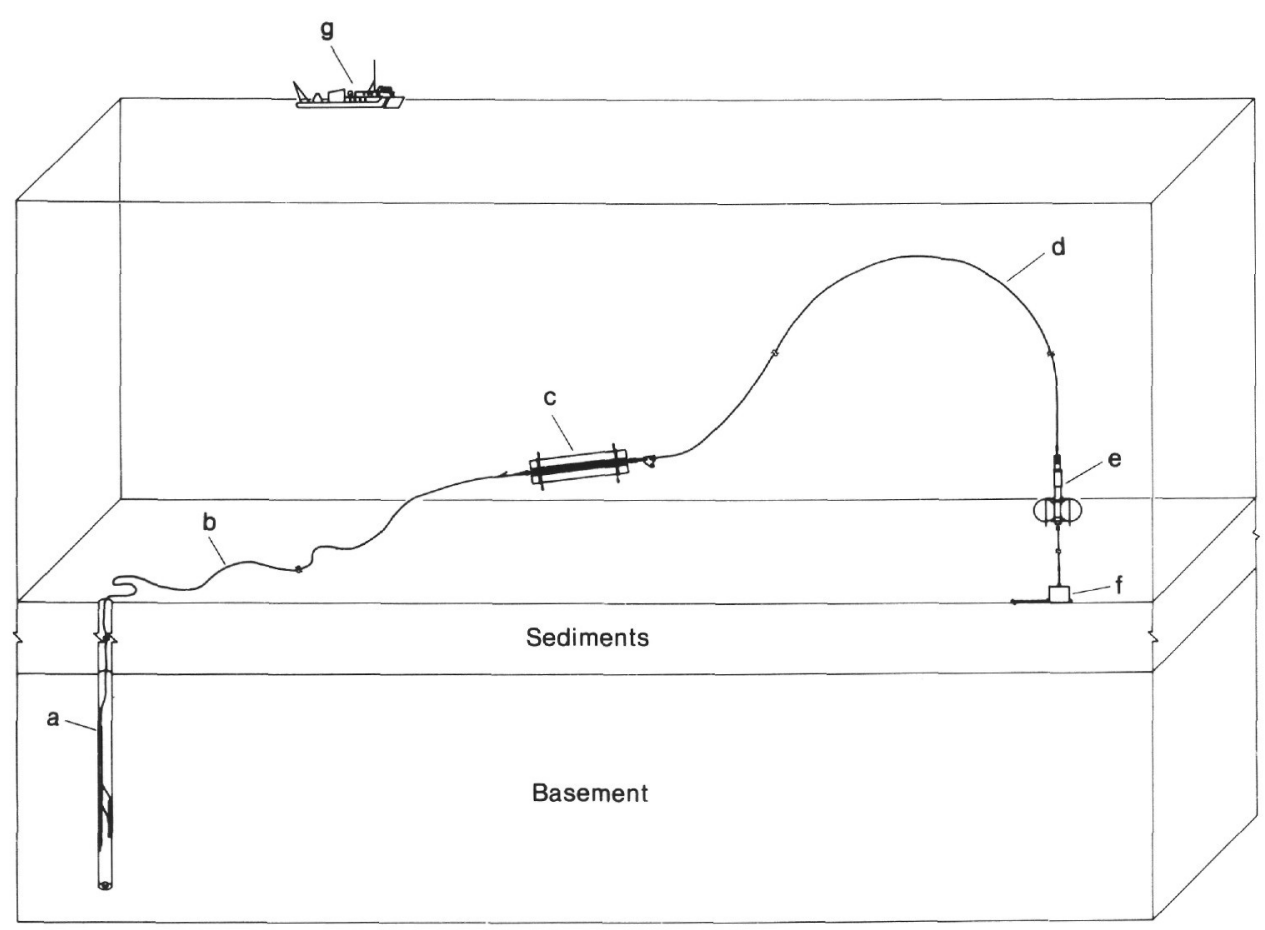

Figure 2. System diagram of the OSS: $a$, borehole with tool; b, electromechanical cable; $c$, recorder package; d, recovery rope; e, anchor buoy; f, anchor; g, recovery ship.

card cages inside the pressure cases (Fig. 6), which are constructed from 7075 -T6 aluminum tubing $(18 \mathrm{~cm}$ outside diameter [OD], $14.5 \mathrm{~cm}$ inside diameter [ID], $190 \mathrm{~cm}$ long). Each pressure case is closed with two endcaps, each of which (Fig. 7) is sealed with two " $O$ " rings (a corner and a radial seal). The recorder package assembly is hot-zinc coated to protect against corrosion.

The upper endcap of each pressure case has two electrical connectors with four conductors per connector. A polyethylene housing is mounted around the connectors to limit their flexure. Two bolts threaded into each endcap through body holes drilled in the pressure case hold the endcaps in place if the battery degasses or other events occur that would cause them to move. A vacuum fitting is placed on each top endcap and the air is evacuated from each pressure case by using a special vacuum fitting tool (Fig. 8). The evacuation removes moist air from the interior of the pressure case, holds the endcaps in place, and insures a good initial low-pressure seal.

The two pressure cases are clamped to a 6061-T6 aluminum rod $2.2 \mathrm{~m}$ long and $6 \mathrm{~cm}$ in diameter. Tension is transferred from the electromechanical cable to the rod through an Evergrip (Preformed Marine Products). The detensioned electromechanical cable lies along the rod and its cablehead is joined to an adapter that connects the conductors to the recording package. The cablehead and adapter are strong enough to withstand the full tension of installation and recovery in the event that the Evergrip fails. An electrical jumper is installed from the adapter to the endcap of the recorder package. Five preformed cable grips, located on the electromechanical cable at 1-m intervals directly below the recorder package, are used to take the cable tension during installation and servicing.
The electronics cage (Fig. 9) and battery cage fit inside the pressure cases. The cages are indexed in position by pins that mate to each top endcap. The cages are constructed of interchangeable modules compatible with other instruments built by HIG. The battery cage is a stack of 7 battery pack modules each consisting of an aluminum frame with a removable battery pack of 6 polyvinylchloride (PVC) tubes, each holding 3 D-cell alkaline batteries, for a total of 18 cells per battery pack. The battery pack cage, holding a total of 126 cells, supplies electric power to the tool for more than two months. The electronics cage includes 4 battery pack modules, a 14-slot printed circuit card cage module, and a tape recorder module. The tape recorder module contains 5 HIGmodified, constant-speed, magnetic-tape cassette recorders (Fig. 10) that are constructed by modifying a small cassette tape transport, installing a 4-track record head and a slow speed DC motor. A speed regulator on each tape recorder drives the motor to insure constant tape speed over a broad range of power supply voltages and ambient temperatures. The tape speed is held constant to within $\pm 1 \%$.

\section{The Recovery System}

The recovery system consists of the recovery rope and anchor package. The recovery rope is braided polypropylene, $3.2 \mathrm{~cm}$ in diameter, with a length greater than 1.5 times the water depth at the installation site and has a breaking strength of $\sim 10,000 \mathrm{~kg}$, which is $\sim 2,500 \mathrm{~kg}$ greater than the strength of the electromechanical cable. Therefore, the cable will break before the rope. The recovery rope, being positively buoyant, floats above the ocean bottom in a catenary and provides enough buoyancy to lift the recorder package a few hundred meters 


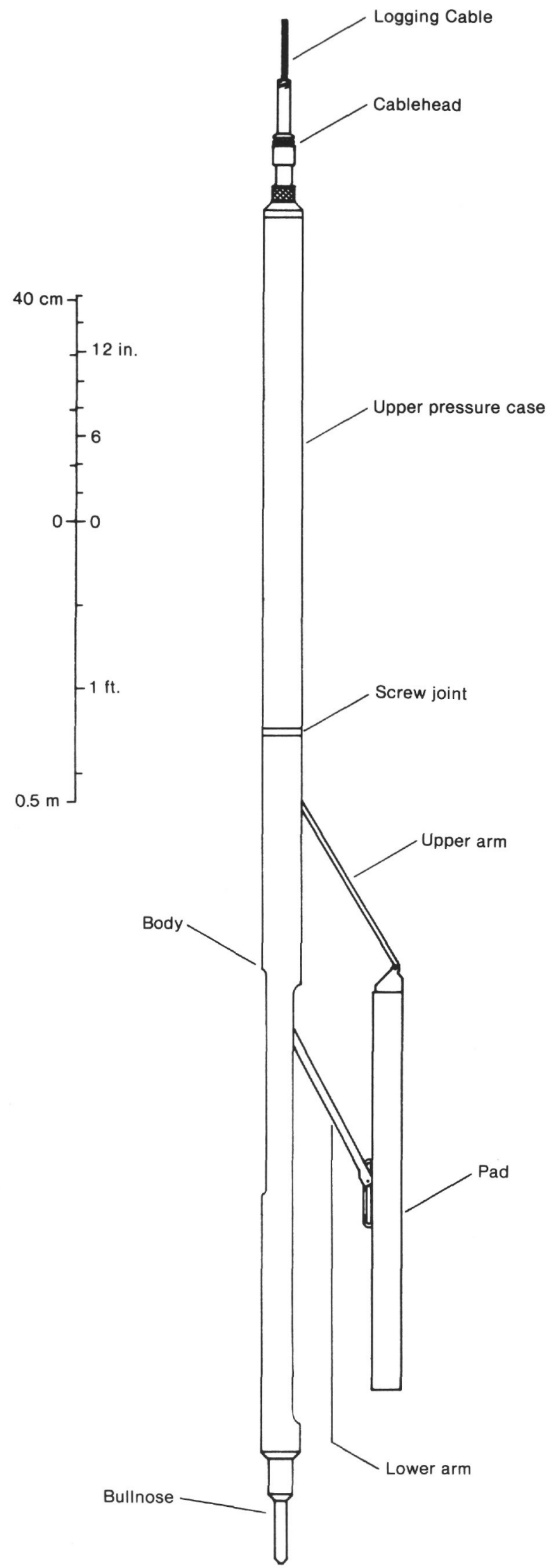

Figure 3. Borehole package (tool) as installed on OSS IV.

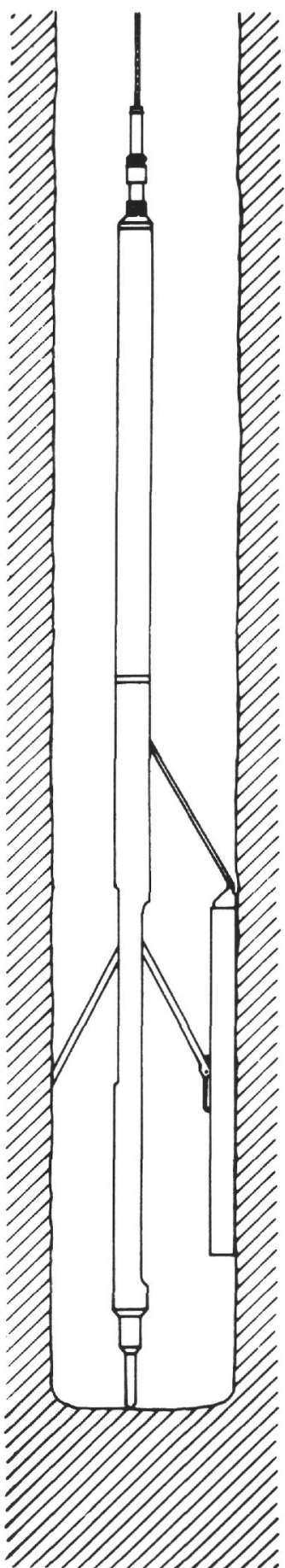

A

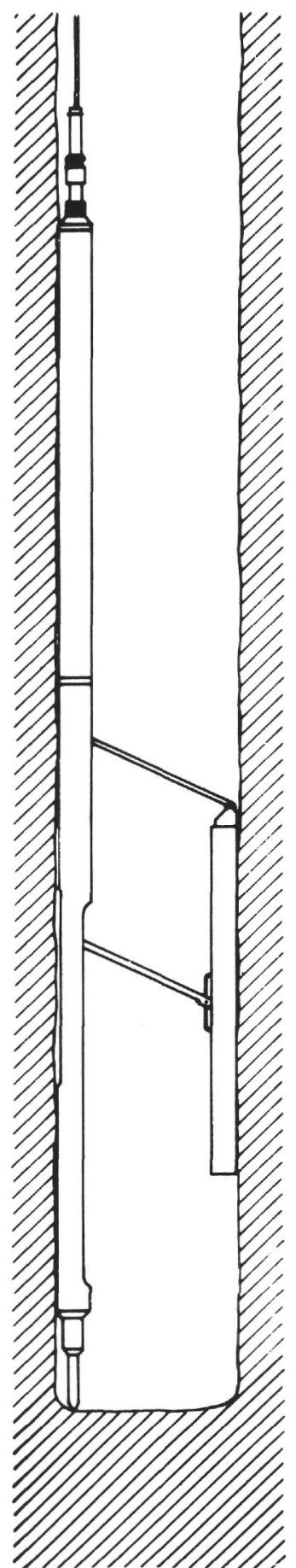

B
Figure 4. Modification of borehole package. A. Original package as supplied by Gearhart Industries. B. HIG modification to improve seismic coupling to borehole.

off the ocean bottom. The anchor package is attached to the other end of the recovery rope with a swivel.

The anchor package consists of the anchor buoy and an expendable anchor (Fig. 11). Two acoustic transponders (Sonatech Model 410) are mounted in a flexible frame. The strain of the anchor assembly is transmitted through a $1.3-\mathrm{cm}$ stainless steel cable connecting the up- 


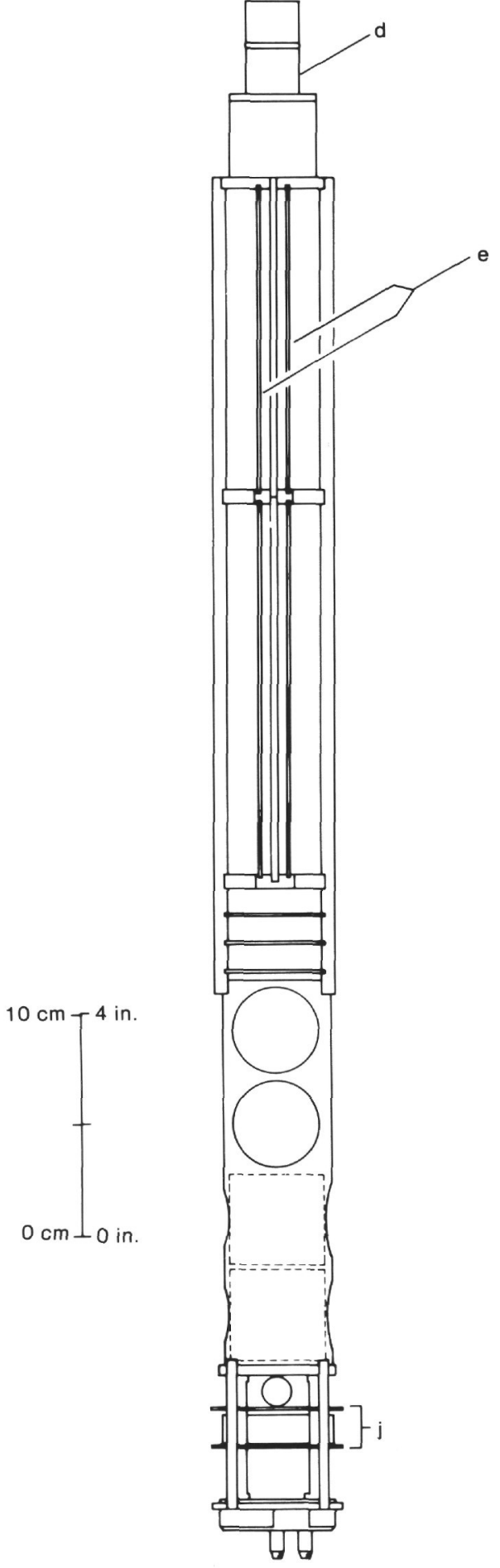

A

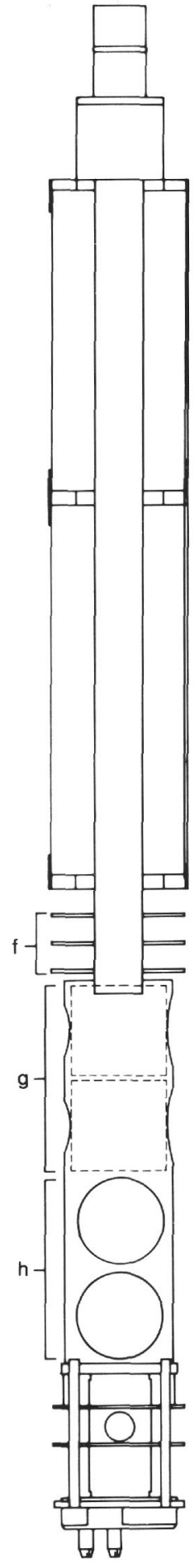

B

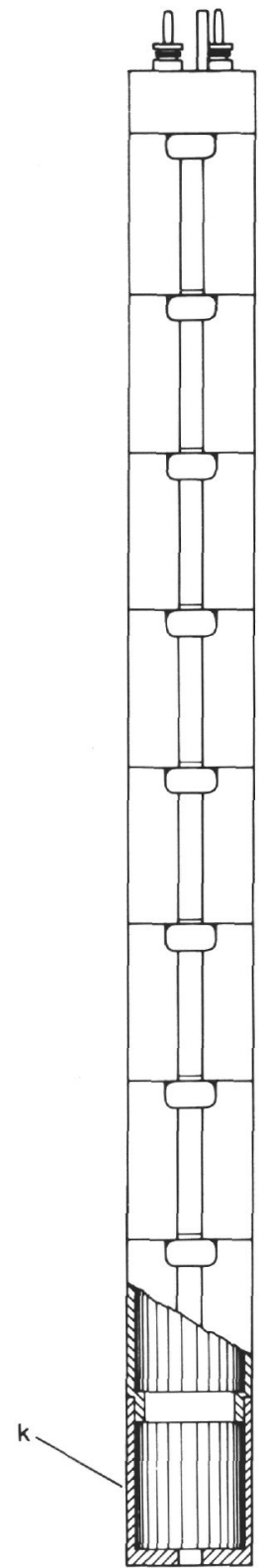

C

Figure 5. Front (A) and side (B) views of the borehole package electronics cage. C. Vertical geophone stack removed from the extended pad. d, cable connector; e, printed circuit boards; f, geophone preamplifier boards; $g$ and $h$, horizontal geophones; $j$, tilt meters; $k$, vertical geophone.

per bracket to the base plate. Two Sonatech standard corroding-wire releases are attached to the bottom of this base plate. On receipt of a valid acoustical command from the recovery ship, voltage is supplied to the uninsulated section of the nichrome wire release. After a few minutes, the exposed wire corrodes away and a chain link is released. Each transponder and release is functionally independent. The anchor assembly is attached to the release package with a pear-shaped ring and shackle. Fifty meters of steel cable in series with a swivel and $5 \mathrm{~m}$ of $1.3-\mathrm{cm}$ chain connect the $900-\mathrm{kg}$ lead anchor to the release assembly. A small Danforth anchor is chained 

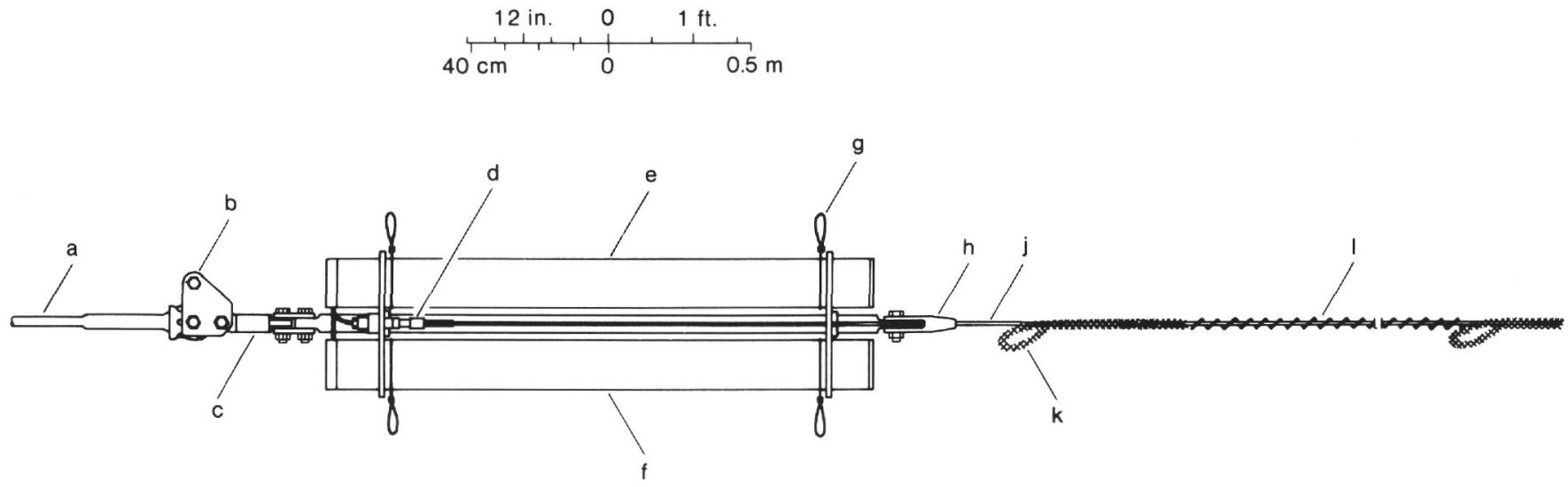

Figure 6. Assembly drawing of the recorder package: a, recovery rope; b, coupler; $c$, swivel; $d$, cablehead; e, electronic pressure case; $f$, battery pressure case; g, wire loops for handling lines; h, Evergrip termination; j, electromechanical cable; $k$, preformed cable grip; 1 , zinc anode rods.
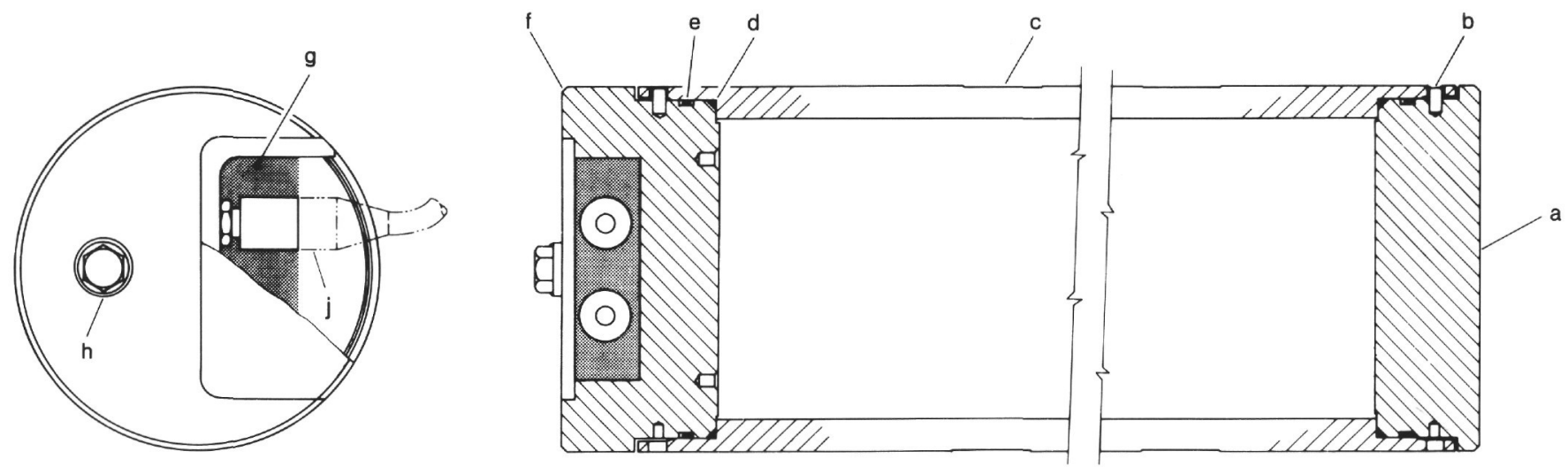

Polyethylene

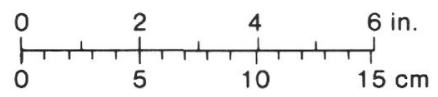

Figure 7. Pressure case detail: a, lower endcap; b, endcap retaining screw; c, pressure case; d, corner seal "O" ring; e, radial seal "O" ring; f, upper endcap; $g$, connector-immobilizing housing; $h$, vacuum fitting; $j$, electrical connectors.

to the lead anchor to increase the drag on the ocean bottom. Two $40-\mathrm{cm}$ spheres attached to the bottom half of the release assembly supply the buoyancy to float the release assembly and the end of the recovery rope to the surface of the ocean. During its ascent, the recovery package is located by means of transponder ranging. The yellow recovery rope can be seen on the surface from moderate distances.

If the anchor is not released, two other recovery techniques are available. The first is to grapple for the recovery rope with a weighted grapple, which is dragged close to the ocean bottom near the anchor package. When either the grapple or the steel winch cable contacts the recovery rope, the rope is rapidly cut or hooked, floats to the surface, and is recovered. The second method, grappling for the electromechanical cable, would result in the destruction of the cable, but so far has not been necessary. All four OSS systems thus far deployed have been recovered.

\section{ELECTRONIC SYSTEMS}

The OSS system electronics may be divided into two subsystems: the borehole package electronics and the recorder package electronics (Fig. 12).

\section{Borehole Package Electronics}

The borehole package electronics are built into the upper pressure case of a modified Gearhart Industries density-logging tool. They consist of four main sections: (1) sensors, (2) floating-point analog/digital (A/D) converter, (3) serial digital logic, (4) power supply and line driver.

\section{Sensor Inputs}

These are pre-scaled for the \pm 2.5 - $\mathrm{V}$ input range of the floating-point A/D converter. The sensors are (a) geophones, (b) tilt meters, (c) temperature sensors, (d) excess current, and (e) pad extension. 


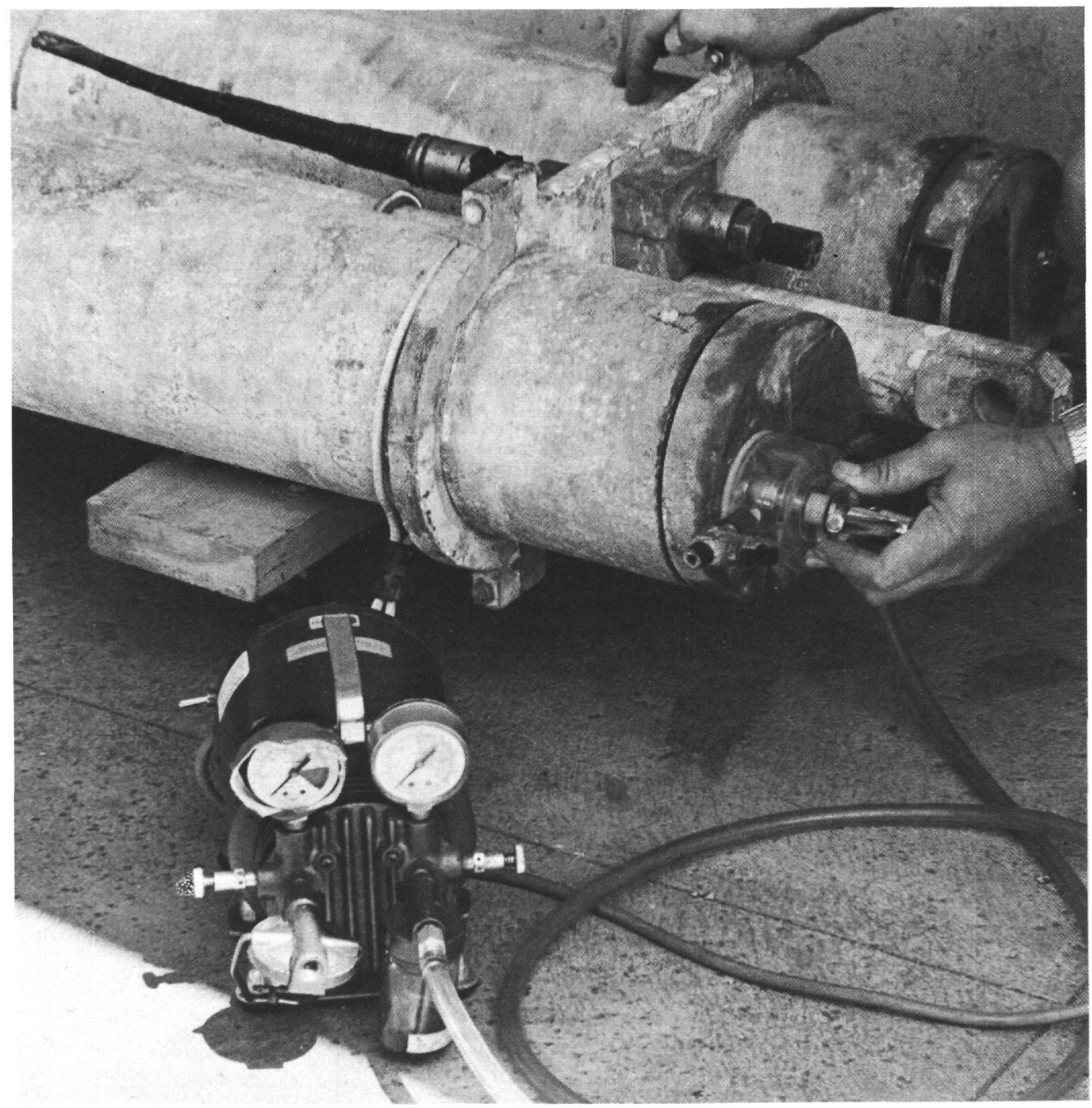

Figure 8. Evacuating the pressure case.

\section{Geophones}

The geophones used are Geospace Model HS-1 with a $4.5-\mathrm{Hz}$ resonance and $5000-\mathrm{ohm}$ coils. Each geophone is individually damped ( 0.5 critical) with a $20,000-\mathrm{ohm}$ resistor.

The vertical sensor stack consists of nine geophones in series, mounted in the extendable pad. Two wires carry the signal into the upper pressure case. The nine geophones provide a sensitivity of $720 \mathrm{~V} / \mathrm{m} / \mathrm{s}$. The preamplifier in the upper pressure case boosts that to $55,000 \mathrm{~V} /$ $\mathrm{m} / \mathrm{s}$. Due to the high impedance of the stack, even slight seawater leakage through the cables can result in substantial signal degradation and DC offset. This problem may be solved by placing the preamplifier in the pad or locating the vertical geophones in the upper pressure case.

The two orthogonal horizontal sensors consist of two HS-1 series-connected geophones (similar to the verticals), providing $160 \mathrm{~V} / \mathrm{m} / \mathrm{s}$ sensitivity. The preamplifiers boost the sensitivity to $53,000 \mathrm{~V} / \mathrm{m} / \mathrm{s}$ (approximately the same as the vertical).

\section{Tilt Meters}

The two tilt sensors are aligned with the corresponding horizontal geophones. The sensors (Fredericks Model 7660) are small, electrolyte-filled glass capsules with three electrical terminals that form one arm of a bridge circuit. Because the electrolyte deteriorates when subjected to a DC current, a $1.5-\mathrm{kHz}$ square-wave $\mathrm{AC}$ excitation is used. The bridge output is synchronously detected, scaled, and filtered with a $0.16-\mathrm{Hz}$ low-pass filter. The overall sensitivity is approximately $7 \mathrm{~V} / \mathrm{rad}$.

\section{Temperature Sensors}

The temperaure sensor (Analog Devices AD590) is an integrated circuit device that produces a current proportional to absolute temperature $(1 \mu \mathrm{A} / \mathrm{K})$. The sensor "zero" output is offset to about $12^{\circ} \mathrm{C}$ so that the $\mathrm{A} / \mathrm{D}$ converter will function on a more sensitive range at the expected hole temperature (see discussion in section 2, later). 

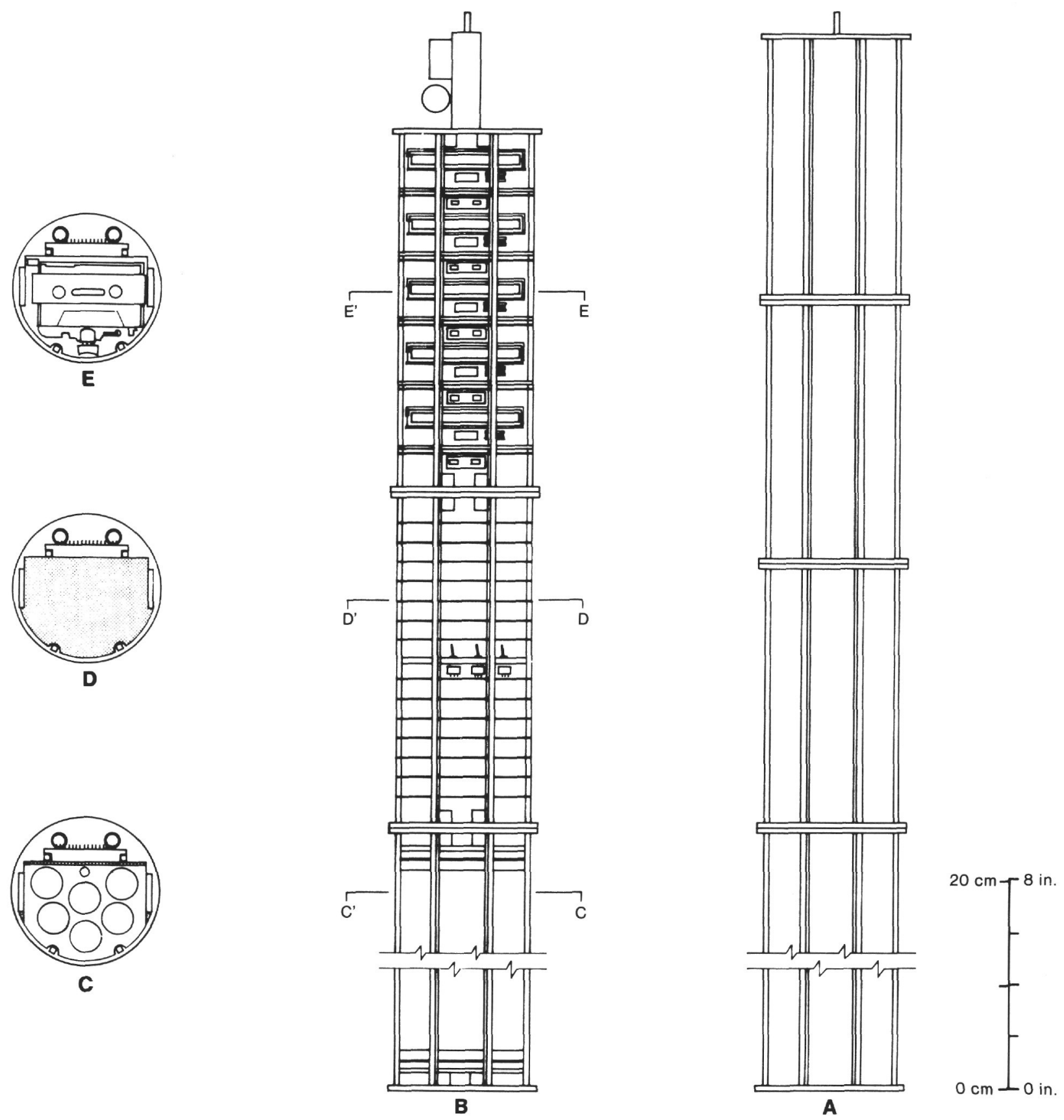

Figure 9. Assembly drawing of the recorder package electronics and battery cages. A. Battery cage. B. Electronics cage. C. Cross section of battery pack module $\left(C^{\prime}-C\right)$. D. Cross section of a printed circuit board module $\left(D^{\prime}-D\right)$. E. Cross section of tape recorder module $\left(\mathrm{E}^{\prime}-\mathrm{E}\right)$.

\section{Excess Current}

The recorder package supplies approximately $40 \mathrm{~mA}$ constant current down the logging cable to a shunt regulator. A resistor senses the excess current shunted by the regulator. This signal is telemetered back to the recorder package with the other signals and provides engineering information on the status of the power supply.

\section{Pad Extension}

A linear potentiometer senses the position of the pad arm to confirm that the tool is seated properly in the borehole. It is operational only while the tool is being monitored in real time at the higher data rate. When the data rate is dropped, power to the potentiometer is turned off.

\section{The Floating-Point Analog To Digital Converter (FPA/D)}

This uses a base-4 floating-point successive approximation conversion with a 9-bit mantissa ( 8 bits plus sign). There are eight exponent ranges (referred to as $\mathrm{e} 0$ to e7). The $\mathrm{e} 0$ range is $2.5 \mathrm{~V}$ full scale, whereas the e 7 range is $156 \mu \mathrm{V}$ full scale. (One least significant bit on the e7 range is $610 \mathrm{nV}$.) (See Table 1.) 


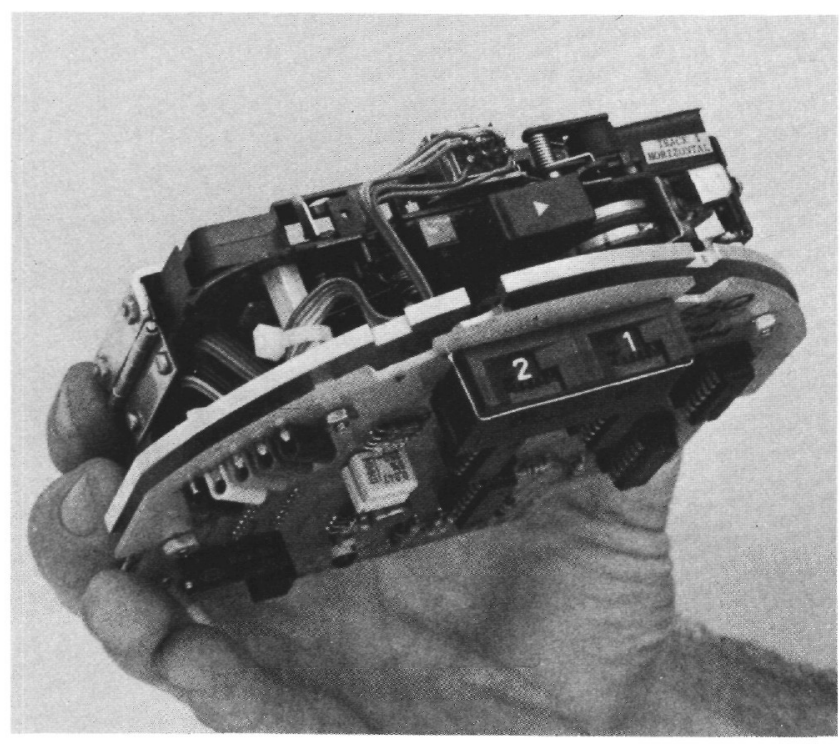

Figure 10. HIG-modified cassette tape recorder. The recorder is preset to start on day 21 and to run at any of four speeds.

The total dynamic range of the converter is $138 \mathrm{~dB}$, and the resolution is $54 \mathrm{~dB}$ (9 bits). The 9-bit mantissa limits the effective resolution to $0.2 \%$ at best, but the base-4 exponent can reduce the resolution to as low as $0.8 \%$ of the value of a sample. The dynamic range is greater than the range of the analog tape recording. The use of a floating-point conversion scheme has a major drawback in the presence of any DC level. If the DC offset is substantially larger than the signal (which is usually the case), the floating-point converter is forced to use a less sensitive conversion range, and the resolution decreases. To minimize this effect, the DC offsets are removed before conversion. The digitized value of the offset of each channel is recalled from memory, converted to analog, and subtracted from the input signal. The DC offset memory stores one measurement (without any DC offset correction) taken on each channel. Each time the DC offset update logic commands an update, this value is stored in CMOS RAM to be used as the DC offset for that channel until it is again updated. The multiplexer, under control of the channel multiplexing logic, selects the next sensor for conversion. The multiplexer is at the summing node input to the A/D converter. The DC offset correction is inserted at the input summing node. This section scales the input (under digital control) for the selected exponent range. There are two successive approximation registers: the first one determines the appropriate exponent range to be used and scales the input (under digital control) for the selected exponent range. The second digitizes the mantissa.

\section{Serial Digital Logic}

\section{Channel Multiplexing Logic}

The data channels are sampled at an overall rate of $200 \mathrm{samples} / \mathrm{s}$ (400 samples/s in high-speed mode). The 16 data channels (8 data channels, 8 DC offset channels) are sequentially sampled according to the hierar- chical scheme shown in Figure 13. The scheme is a modified four-channel scanning sequence with four tiers. The highest tier channels (the geophones) are sampled at 50 or $100 \mathrm{samples} / \mathrm{s}$. The second tier (tilts and arm extension) are sampled at one-fourth that rate $(12.5$ or 25 samples/s). Tier three (temperature and excess current) are sampled at $1 / 16$ rate $(3.125$ samples/s or 6.25 sam$\mathrm{ple} / \mathrm{s})$. The last tier transmits each of the eight DC offset channels every 1.280 or $0.64 \mathrm{~s}$. The channel assignments are listed in Table 2.

\section{Offset Update Logic}

During real-time monitoring of the data at the higher sampling rate, the DC offset of all channels is updated once every $15 \mathrm{~s}$. When the tool is switched to normal data rate, offset updates are made once every $30 \mathrm{~min}$. This insures that each DC offset value can be recorded in the time code before it changes.

\section{Word Encoding}

The digitized signals are encoded as 16-bit words consisting of a four-bit channel number, three-bit exponent, one-bit polarity, and eight-bit mantissa. (See Fig. 14.) One start bit and one stop bit are added to maintain synchronization. The 18 bits are delay-modulated and transmitted to the recorder package.

\section{Power Supply and Line Driver}

A constant current of approximately $40 \mathrm{~mA}$ is supplied by the recorder package. A shunt regulator supplies about $10 \mathrm{~V}$ to the line driver and the voltage regulators. A CMOS buffer driven by the $28.8-\mathrm{kHz}$ clock is used as an inverter to generate the negative supply voltages. Reference amplifier A1 (Fig. 15B) supplies a precision $5.120-V$ reference. Separate buffer amplifiers regulate the positive analog and digital supply voltages, whereas an inverting amplifier and a buffer regulate the negative analog and digital supply voltages.

If current in excess of $45 \mathrm{~mA}$ is detected by the regulator, the clock frequency is automatically doubled, increasing the sampling rate by a factor of 2 for real-time monitoring.

The line driver is designed to drive the heavy capacitive load presented by the $10-\mathrm{km}$ electromechanical cable. A decoupling network and carefully planned printed circuit board layout minimize the coupling of transients from the line driver into the very sensitive geophone amplifiers.

The seven-conductor armored cable connecting the tool to the recorder package, the cable normally used for logging on the Glomar Challenger, was chosen because of its compatibility with Challenger hardware and the considerable experience of the technical staff with connectors and splices. Although only four conductors are required by the tool, all seven are used for redundancy.

\section{Recorder Package Electronics}

The recorder package consists of four main sections: (1) battery packs and power supplies, (2) data receiver, (3) floating-point digital/analog converter and (4) delayed-turn-on tape recorders. 

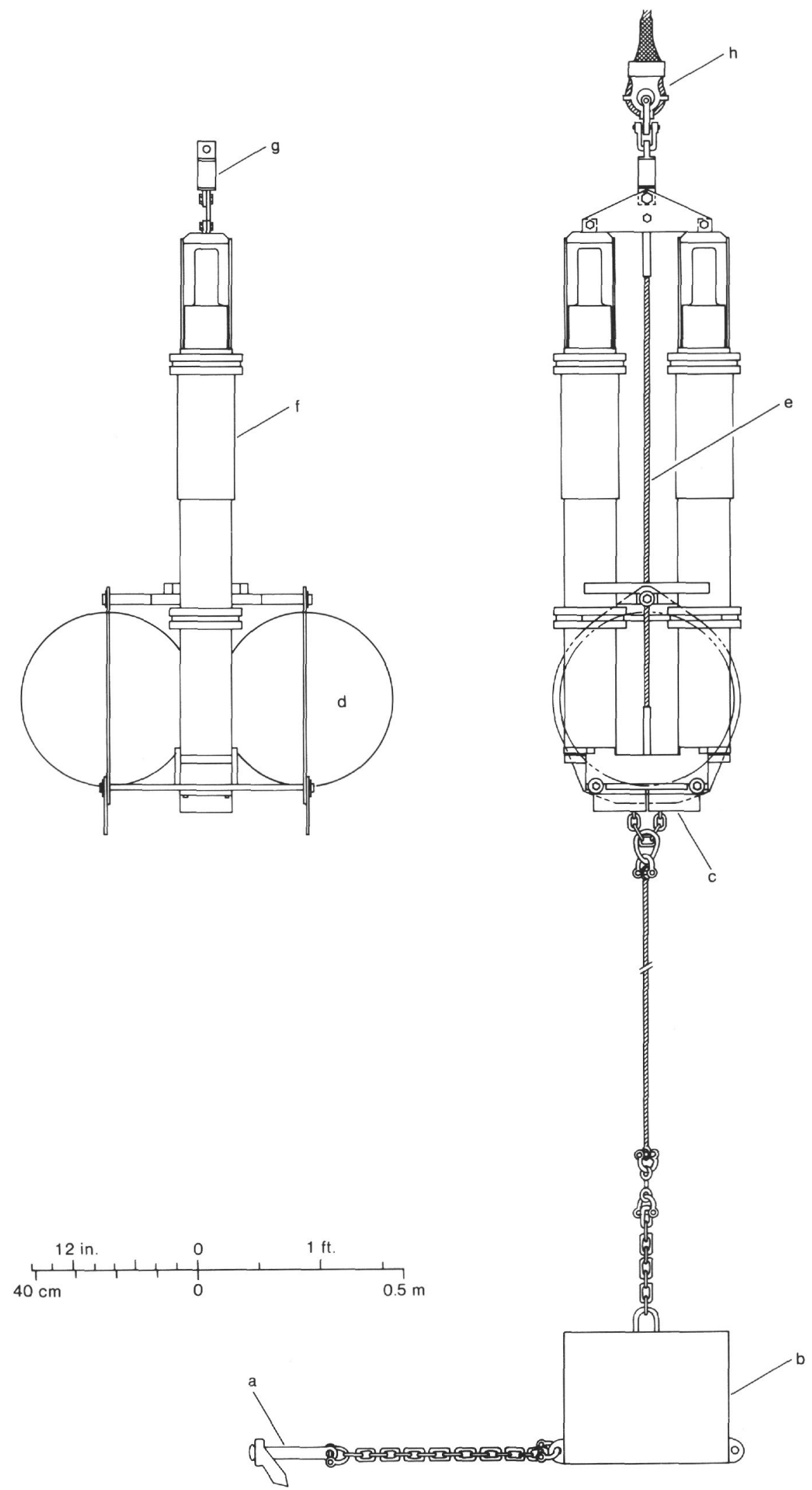

Figure 11. The anchor buoy with anchors: a, Danforth anchor; b, lead anchor; c, release mechanisms; d, 40-cm glass spheres; e, 1.3-cm stainless steel load-bearing cable; f, transponders; $g$, swivel; $h$, recovery rope. 


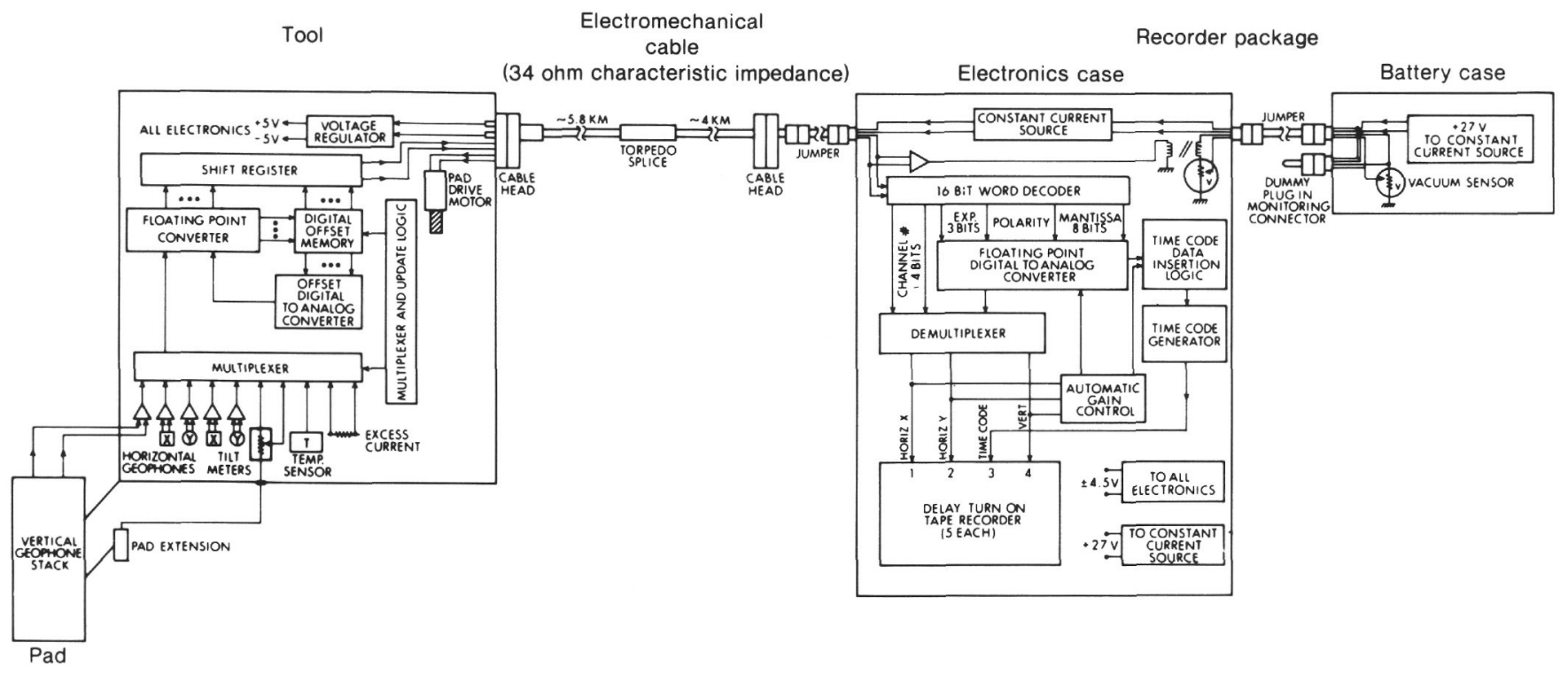

Figure 12. Block diagram of the OSS electronics system.

Table 1. Floating-point conversion ranges.

\begin{tabular}{|c|c|c|c|c|}
\hline Exponent & \multicolumn{2}{|c|}{ Maximum } & \multicolumn{2}{|c|}{ Minimum } \\
\hline $\mathrm{e} 0$ & 2.5 & V & 10 & $\mathrm{mV}$ \\
\hline el & 640 & $\mathrm{mV}$ & 2.5 & $\mathrm{mV}$ \\
\hline $\mathrm{e} 2$ & 160 & $\mathrm{mV}$ & 625 & $\mu V$ \\
\hline e3 & 40 & $\mathrm{mV}$ & 156 & $\mu V$ \\
\hline e4 & 10 & $\mathrm{mV}$ & 39 & $\mu V$ \\
\hline e5 & 2.5 & $\mathrm{mV}$ & 9.8 & $\mu \mathrm{V}$ \\
\hline e6 & 625 & $\mu \mathrm{V}$ & 2.44 & $4 \mu \mathrm{V}$ \\
\hline e7 & 156 & $5 \mu \mathrm{V}$ & .61 & $\mu V$ \\
\hline
\end{tabular}

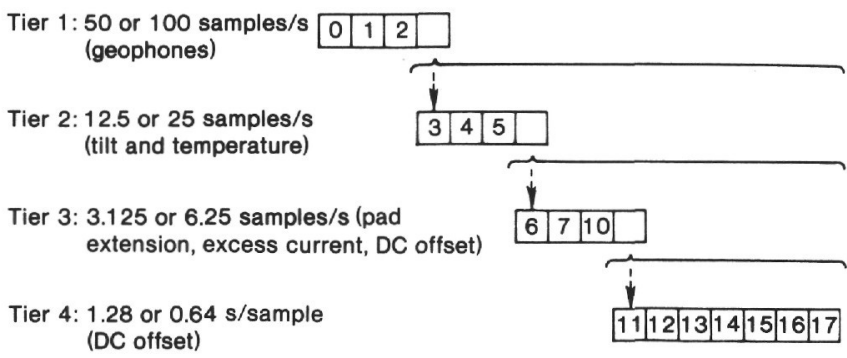

Sampling Sequence

$01230124012501260123 \ldots$

Figure 13. Sampling hierarchy of the channel multiplexing.

\section{Battery Packs}

Each pack has six tubes with three alkaline D cells $(4.5 \mathrm{~V})$ each. The available power in three of the four packs in one pressure case is divided into separate supplies for the electronics and the tape recorder motors. The individual 4.5-volt tubes are distributed in proportion to the relative ampere-hour requirements. The fourth battery pack is connected with all six tubes in series, forming a 27-volt tool supply to run the tool during testing when the second pressure case (with the main 27-volt supply) is not connected.
Table 2. OSS IV channel assignments.

\begin{tabular}{|c|c|}
\hline $\begin{array}{l}\text { Channel } \\
\text { (octal) }\end{array}$ & Signal \\
\hline 0 & Vertical geophones \\
\hline 1 & Horizontal geophones (parallel) \\
\hline 2 & Horizontal geophones (perpendicular) \\
\hline 3 & Tilt (parallel) \\
\hline 4 & Tilt (perpendicular) \\
\hline 5 & Temperature \\
\hline 6 & Pad extension \\
\hline 7 & Excess current \\
\hline 10 & DC offset channel: 0 \\
\hline 11 & 1 \\
\hline 12 & 2 \\
\hline 13 & 3 \\
\hline 14 & 4 \\
\hline 15 & 5 \\
\hline 16 & 6 \\
\hline 17 & 7 \\
\hline
\end{tabular}

The second pressure case of the recorder package contains 7 battery packs (18 alkaline D-cells each) connected as 27-volt supplies. The total of 56 ampere-hours of battery capacity is sufficient to power the tool for $65+$ days recording time.

\section{Data Receiver}

The waveform of the digital telemetry from the tool is reshaped (see Line Driver Modifications section) and passed to a delay demodulator that recovers the bit stream. The word decoder synchronizes the start and stop bits and latches the 16-bit parallel word (Fig. 14), which is passed to the floating-point digital/analog converter.

\section{Converter}

The analog voltage sampled by the tool is converted back to analog form $10 \mathrm{~ms}$ later to be recorded by the delayed-turn-on (DTO) tape recorders. The output of the floating-point digital to analog converter (FPD/A) goes to automatic gain control (AGC) circuits similar to those 


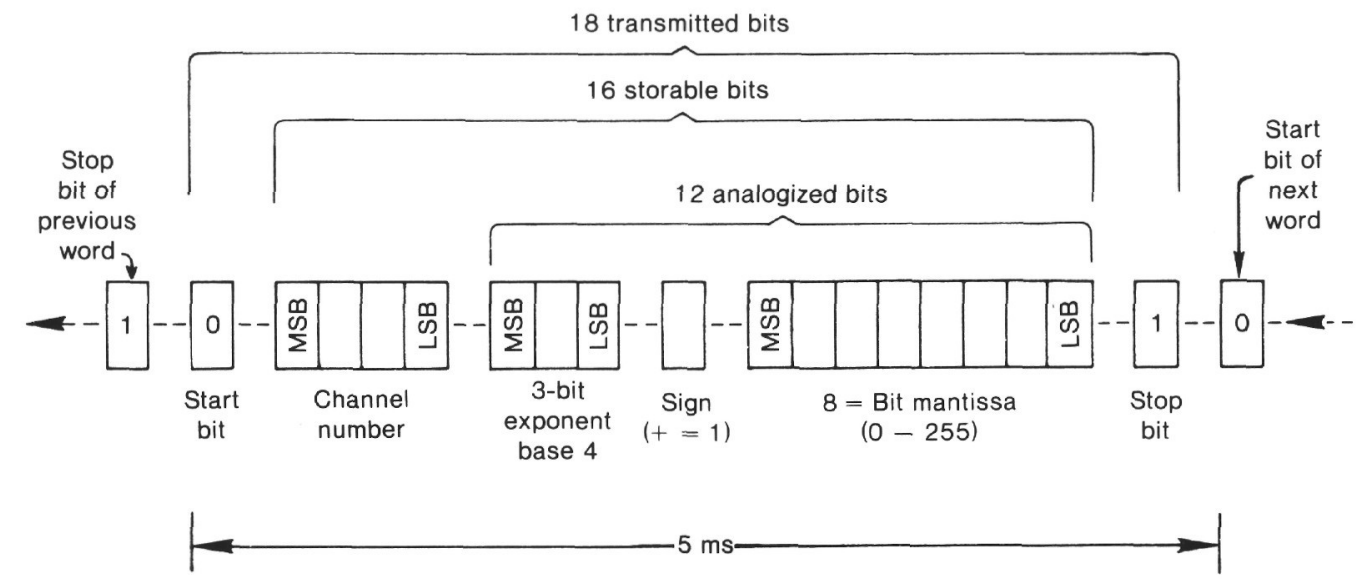

Figure 14. Order of telemetered word bits (Duennebier and Blackinton, 1983).

A

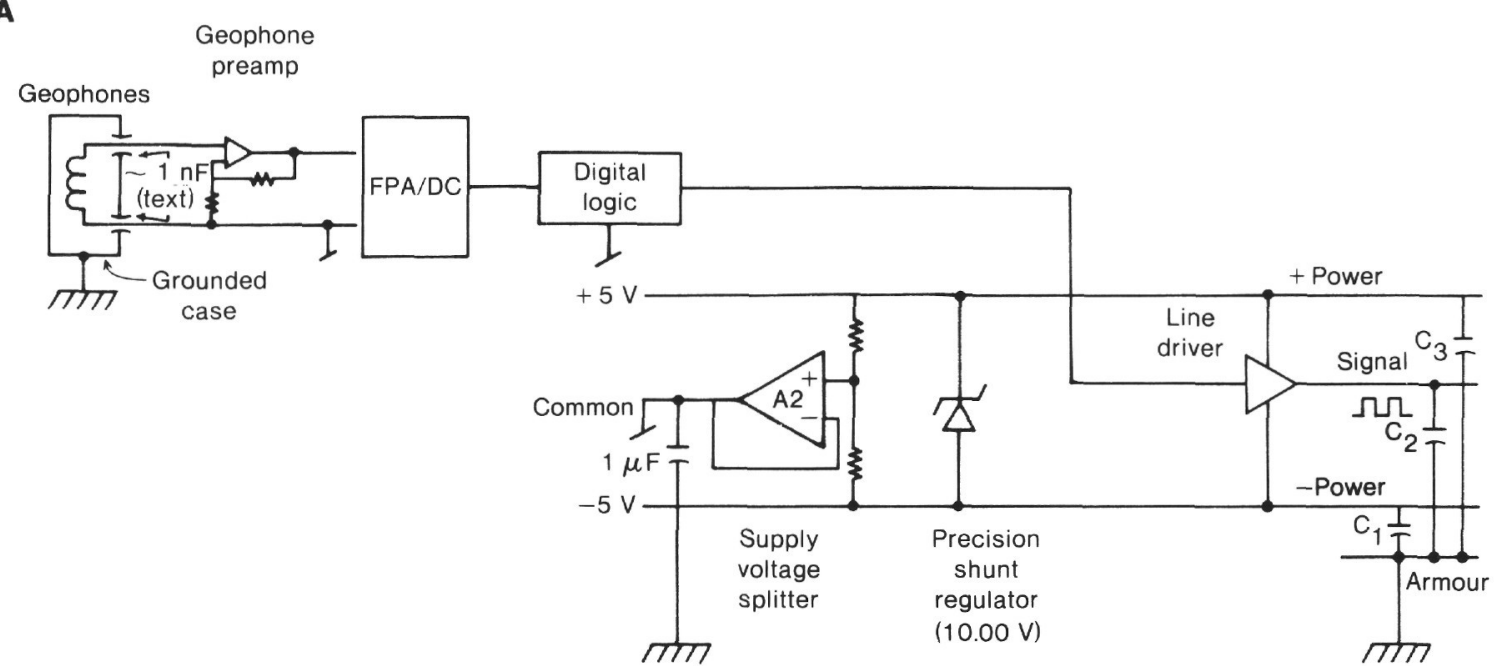

B

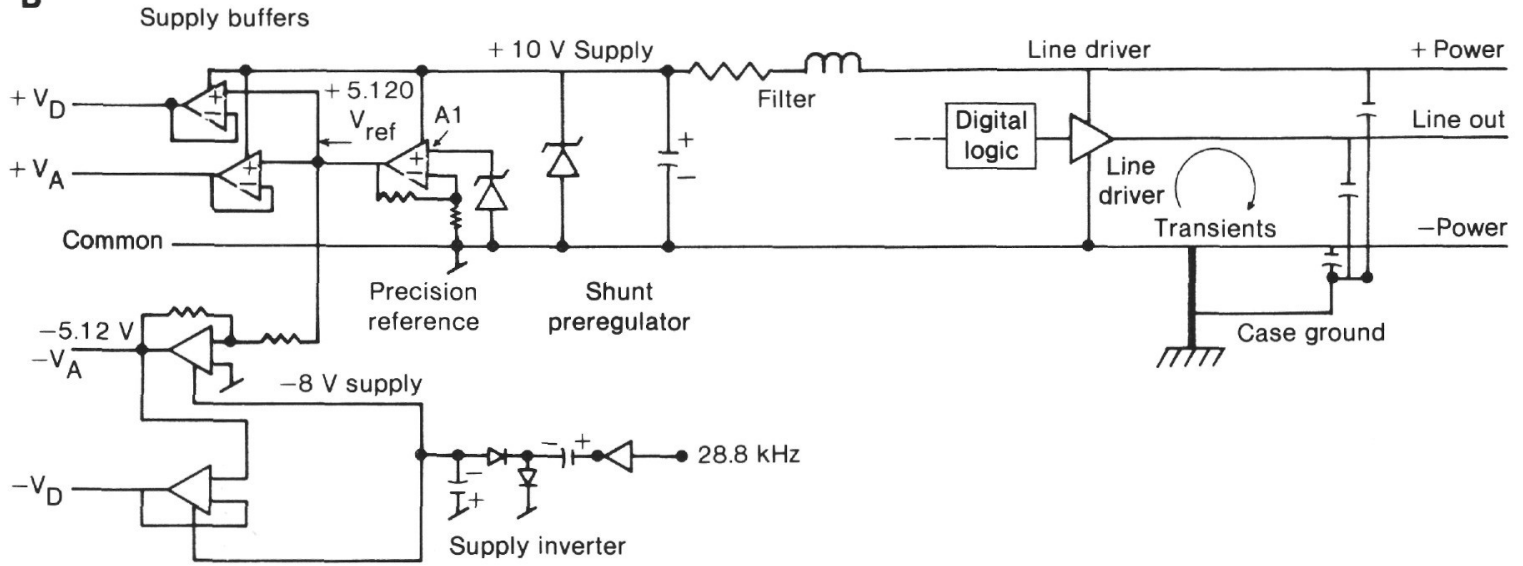

Figure 15. Power supply and line driver, (A) before modifications, (B) after modifications. 
used in the HIG Ocean-Bottom Seismometers. If the 2min. average noise level is outside the lower $12 \mathrm{~dB}$ of the $40-\mathrm{dB}$ range of the analog tape recorders, the gain will be readjusted in 12-dB steps (Table 3) at the beginning of the next minute. Thus the 132-dB dynamic range of the floating-point $\mathrm{A} / \mathrm{D}$ converter in the tool is compressed to fit the 40-dB dynamic range of the tape (Duennebier and Blackinton, 1983). The AGC system fixes the seismic background noise above the tape noise so that the smallest signals always will be recorded; an unfortunate consequence is that large signals may be clipped until the AGC responds. The absolute level of the signal is continuously recoverable because the FPD/A gain is allowed to change only at the start of a minute, and the gain for each minute is coded into the last $10 \mathrm{~s}$ of that minute's modified IRIG-H time code (Fig. 16).

\begin{tabular}{lr}
$\begin{array}{c}\text { Table 3. } \\
\text { gain control gain } \\
\text { steps. }\end{array}$ & $\begin{array}{r}\text { Automatic } \\
\text { Step }\end{array}$ \\
\hline 0 & Gain (dB) \\
1 & 4 \\
2 & +16 \\
3 & +28 \\
4 & +40 \\
5 & +52 \\
6 & +64 \\
7 & +76 \\
& +88 \\
\hline a Gain from & geophone \\
preamplifier & output to \\
analog tape recorder in- \\
put.
\end{tabular}

\section{Delayed-Turn-On Tape Recorders}

These are almost identical to the recorders used in the standard HIG Ocean-Bottom Seismometers. The recorder package contains 5 recorders, each capable of continuous recording of data for up to 14 days. The delayedturn-on circuit of each recorder allows it to be preset to turn on after an integer number of days. Allowing one day overlap between tapes, the 5 recorders, loaded with C-90 tapes provide 66 days of continuous, uninterrupted, analog data recording. Channel assignments are as follows:

\begin{tabular}{cl} 
Channel & \multicolumn{1}{c}{ Assignment } \\
1 & Horizontal X geophones and minute mark \\
2 & Horizontal Y geophones \\
3 & Time code \\
4 & Vertical geophones
\end{tabular}

The 10-Hz IRIG-H time code is recorded on channel 3 and a 1-s burst of $10-\mathrm{Hz}$ tone is added to channel 1 as a minute mark. This allows precise adjustment of the playback head to reduce head skew and insure phase alignment of the seismic signals. The clock is set to Coordinated Universal Time before deployment and any residual time offset is noted. If the clock is still running (i.e., the batteries are not drained) at recovery time, the offset from universal time is again measured to make a firstorder correction for clock drift.

Digital data from all 16 channels are coded into seconds $40-48$ of the time code. Channel number and exponent are sent on one minute and the corresponding mantissa on the next. Thus the value of every channel is recorded once every $32 \mathrm{~min}$.

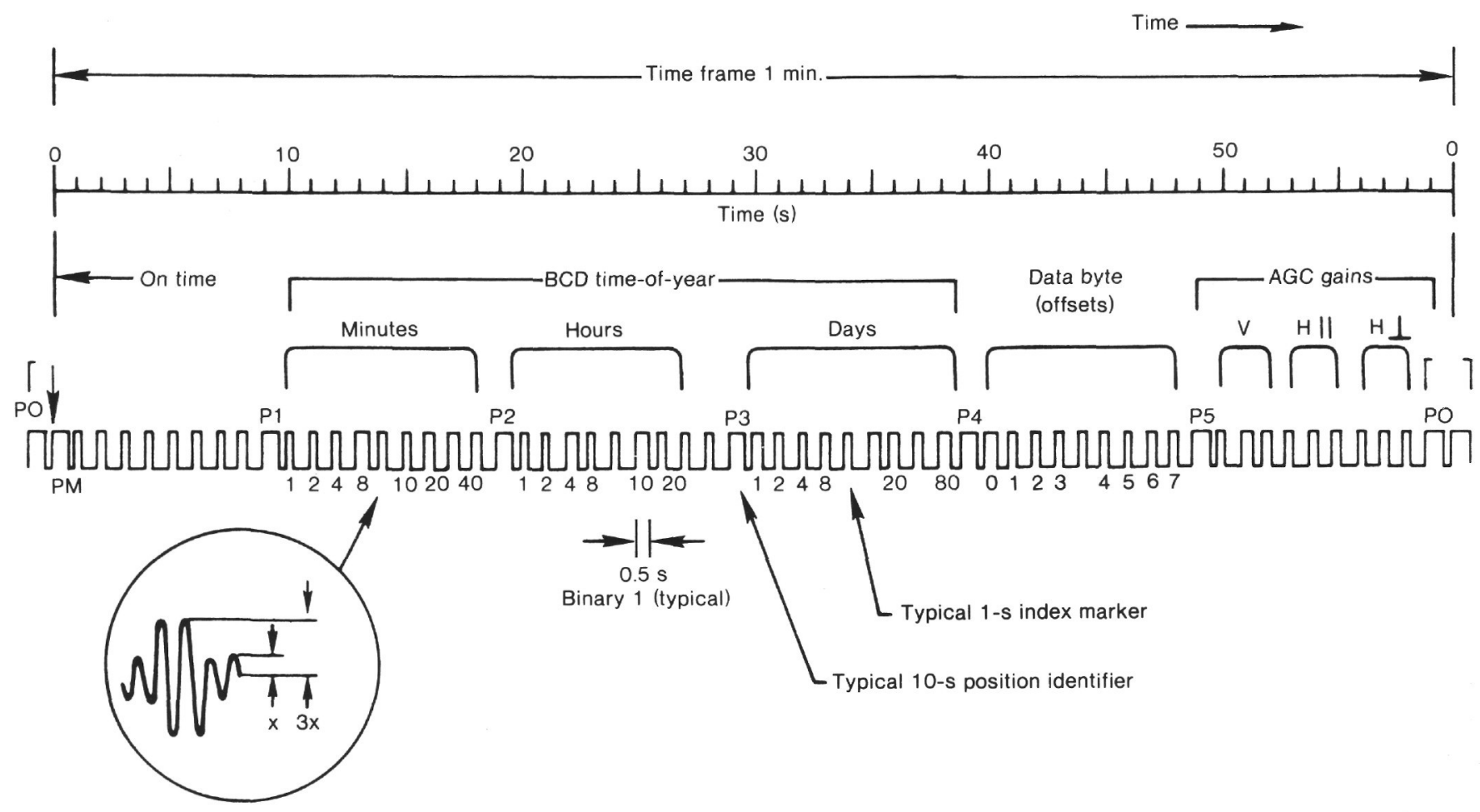

Figure 16. Modified IRIG-H, 10- $\mathrm{Hz}$ time code used for all OSS installations (Duennebier and Blackinton, 1983). 


\section{REALTIME SHIPBOARD RECORDING SYSTEM}

The tool may be connected, through the electromechanical cable, to a test box to monitor its performance and the data in real time. This is done when the tool is first deployed and during servicing of the recorder package. The test box contains much of the circuitry of the recorder package plus numerous test functions; it provides for displaying and recording the data in digital and analog form.

The data may be recorded in a variety of formats. As they are transmitted up the logging cable in delay-modulated digital format, they may be recorded directly on a good-quality analog tape recorder. Modified IRIG-H time code from the recorder package and the ship's clock (also on IRIG code) are also recorded on two other tracks of the tape. This tape, subsequently, may be played back into the test box and decoded as if the tool were connected to the test box. This recording method has the advantage of maintaining the full fidelity of the digital signal.

The serial digital signal is decoded into parallel 16-bit words in the test box. These data words are accessed through a parallel interface into a TRS-80 Model III microcomputer, again with full digital dynamic range. The computer monitors the slow data channels and prints out their values in tabular form. During refraction line shooting, all of the digitized data from individual shots are digitally recorded on 51/4-in. floppy disks and are immediately available for processing or plotting.

Analog outputs from the test box may be recorded on an FM analog recorder or on a strip chart recorder. The strip chart provides an immediate visual monitor of the tool's performance, and the FM recorder provides data in a form appropriate for further analog processing. Because these data are processed through the FPD/A converter in the test box, their fidelity may be somewhat less than that of the original data.

\section{OSS IV MODIFICATIONS}

\section{Power Supply Modifications}

When OSS III was deployed in February 1981, it experienced severe noise problems on the data which had not been encountered while the instrument was being developed or in any of the precruise tests. At first the source was not obvious. It became evident that the digitized data show very strongly preferred states. The noise seemed to be a heavily aliased high-frequency signal. The source was eventually traced to a system grounding problem, which is shown in a simplified diagram in Figure 15A. Because of this noise, the tool was pulled from the hole one day after installation and the recorder package was not installed.

The analog circuits require symmetrical supplies, but it was desirable to supply single-polarity power down the logging cable with a single current regulator. The recorder package supplies about $40 \mathrm{~mA}$ of constant current. In OSS I, II, and III, an active shunt regulator regulated the voltage in the tool to $10.00 \mathrm{~V}$ (Fig. 15A). Operational amplifier A2 is a supply splitter. The common supply point for the circuit, therefore, floats $5 \mathrm{~V}$ above ground.

All of this worked quite satisfactorily in OSS I and II but not in OSS III because of an undocumented feature of the geophones. The two electrical terminals of some of the HS-1 geophones are simple hermetic seal feedthroughs; on others, Geospace used 1-nF feedthrough capacitors (Fig. 15A). The geophones used in the OSS III installation turned out to be ones with the feedthrough capacitors. Increasing the number of geophones in the vertical stack from 2 (OSS I and II) to 9 (OSS III) greatly increased the problem, which had not been noticed during OSS I and II.

The problem did not actually become noticeable until the line driver was required to drive the $10-\mathrm{km}$ logging cable, which presents a substantial, primarily capacitive load of over $2.4 \mu \mathrm{F}$. The heavy transient currents required to drive the digital signal up the cable caused spikes in the supply voltage common ground. Since the cases of the geophones were grounded to the tool case, these transients were coupled directly to the input of the high-gain preamplifiers; these amplified transients heavily masked the seismic signals and caused severe aliasing in the analog-to-digital converter. The converter was attempting to digitize microvolt signals on which were superimposed transient spikes in the high-millivolt range at the 3.5$\mathrm{kHz}$ clock rate.

The solution to this problem required a redesign of the power supply in the tool (see Fig. 15B). An inverter driven from the high-frequency $(28.8-\mathrm{kHz})$ clock oscillator generates the negative supply voltages. This allows the circuit common ground voltage to be at case ground potential. Regulators provide the working voltages for the digital circuits and the reference voltage for the FPA/D converter. Very careful decoupling of the power supply lines at various selected points minimized the coupling of the line-driver transients into the sensitive geophone amplifiers.

The critical grounding point at the geophone preamplifiers was thoroughly strapped to the instrument frame. Even so, a small amount of residual, transient feedthrough still seems to remain at the most sensitive (e7) range of the analog-to-digital converter. This noise seems to be the cause of some system noise in OSS IV, at a level unfortunately close to the seismic background noise at high frequencies.

\section{Line Driver Modifications}

The $10 \mathrm{~km}$ of electromechanical cable connecting the tool to the recorder package is a lossy transmission line with a characteristic impedance of approximately 35 ohms. The line driver in the tool drives a $10-\mathrm{V}$ square wave at about $3.5-\mathrm{kHz}$ into this line. The waveform arrives at the recorder package (Fig. 17) attenuated to about $0.9 \mathrm{~V}$ and may be thought of as a fast step wave propagating along a lossy transmission line. Because the line is not terminated in its characteristic impedance, reflections occur. The "slow" portion of the waveform can be viewed as the charging of the distributed capacitance of the cable through its distributed resistance toward the final value of $10 \mathrm{~V}$. Reshaping this waveform with a zero 


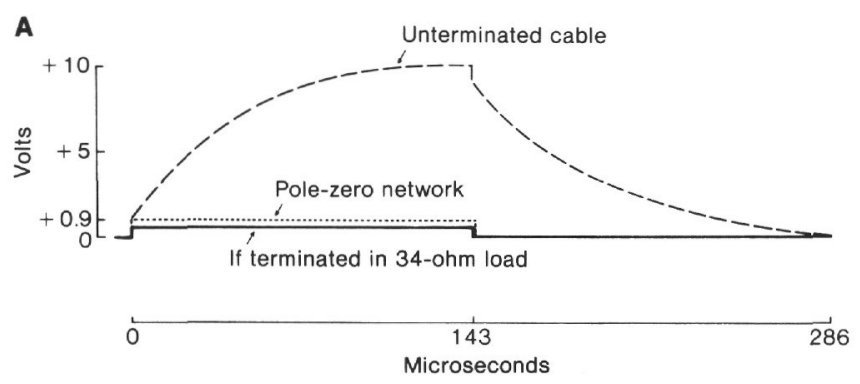

B

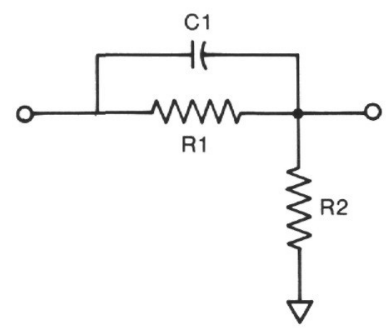

Figure 17. A. Line waveforms arriving at the recorder package. B. RC circuit.

crossing detector (an overdriven amplifier) or a Schmitt trigger resulted in enough jitter to make the signal reconstruction marginal.

One obvious way to restore a good square-wave shape at the recorder package would be to terminate the line in its characteristic impedance. This approach has two disadvantages: it would load the desired signal transition to one-half amplitude and it would significantly increase the drain on the battery by the line driver.

The Laplace transform of the waveform shown in Figure $17 \mathrm{~A}$ is

$$
F 1(s)=\frac{1}{s}-\frac{(1-k)}{(s+b)}=\frac{k(s+b / k)}{s(s+b)}
$$

where $\mathrm{s}=\sigma+\mathrm{jw}, \mathbf{k}=\mathbf{0 . 0 9}$ (relative amplitude of attenuated step function), $\mathrm{b}=1 / \tau$, and $\tau=$ rise time of wave form on unterminated cable.

The undesired pole at $(\mathrm{s}+\mathrm{b})$ can be eliminated with a pole-zero cancelling network with a transfer function of the form:

$$
F 2(s)=\frac{(s+c)}{(s+d)}
$$

where $c=b$ and $d=b / k$.

$$
\text { zero: } c=\frac{1}{\left(\frac{R_{1} R_{2}}{R_{1}+R_{2}}\right) C_{1}}
$$

$$
\text { pole: } \mathrm{d}=\frac{1}{\mathrm{R}_{1} \mathrm{C}_{1}}
$$

The resulting output is

$$
F 3(s)=F 1(s) \times F 2(2)=\frac{k(s+b / k)}{s(s+b)} \times \frac{(s+c)}{(s+d)}=\frac{k}{s}
$$

where F3(s) is the desired step response. This network achieves the desired wave-shaping without increasing the drain on the battery.

If the time constant $\mathrm{R} 1 \mathrm{Cl}$ is adjusted to match the time constant of the exponential portion of the waveform, and the ratio $R 2 /(R 1+R 2)$ is equal to the attenuation of the transmission line, then the recovered waveform is essentially a square wave.

\section{CD4053 Multiplexer Problem}

A secondary noise problem arises from some (again underdocumented) features in some of the CMOS integrated circuits. The CD4053 multiplexers produced a rather heavy negative switching transient (Fig. 18). Once these were identified, some minor circuit changes were required to minimize this effect. The transients have a low source impedance $(<200 \mathrm{ohm})$ but they are only about $50 \mathrm{~ns}$ wide.

\section{Modifications in the Placement of the Temperature Sensor}

In OSS III, the temperature sensor package was mounted on the card-support frame of the electronics package in the tool. Coupling to the hole temperature was slow,

\section{A}

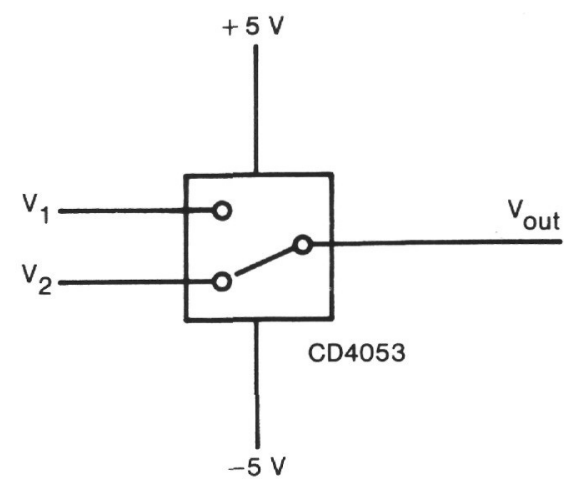

B

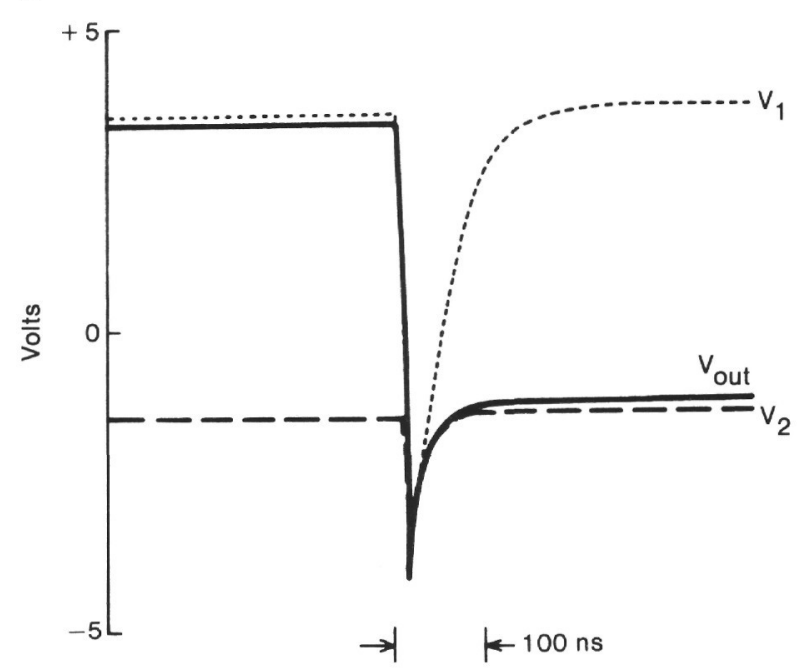

Figure 18. CD4053 analog switching transients. A. Functional diagram of CD4053. B. Switching transient. 
and some slight heat from the voltage regulators may have affected the temperature readings. In OSS IV, the temperature sensor was mounted at the lower end of the pressure case, where it is well away from heat sources and well coupled to the hole temperature.

\section{+ / - Balance on $\mathrm{e} 1$ and $\mathrm{e} 0$ Ranges}

The CD4053 analog switches are slightly nonlinear and are asymmetrical for large voltage excursions. Consequently the DC offset correction for large offset ( $>160$ $\mathrm{mV}$ ) does not remove it all. Some redesign of the offset circuit could improve the correction.

\section{TESTING THE SYSTEM}

The most valuable lesson from the installation of OSS I, II, and III was the need for more testing of the system. This seemingly obvious need is sometimes difficult to achieve, mainly because of short funding cycles and the constant pressure to lower costs.

In spite of these difficulties, a testing program was followed for OSS IV. The system was tested in four phases: (1) previous field installations (OSS I, II, and III), (2) bench tests, (3) subsystem calibration and tests, (4) shallow-water systems test.

Phase 1 was possible because the few changes made between OSS III and OSS IV were to correct problems noted during the OSS III installations. Phase 2 involved testing the various electronic and battery cages on the bench with a simulated $10-\mathrm{km}$ electromechanical cable. It was during this phase that the majority of the OSS III problems were identified and corrected.

Phase 3 involved four steps. First, individual geophones and tilt meters were tested and calibrated on the shaker table with mechanical signal levels expected after installation (Duennebier et al., 1984). After these individual sensors were calibrated, the complete tool was assembled and tested on the shaker table. Second, the assembled tool was operated in a water bath. The temperature of the bath was varied between $0^{\circ} \mathrm{C}$ and $98^{\circ} \mathrm{C}$ to calibrate the temperature sensors as well as to identify any temperature-sensitive components or solder joints. Third, the operating temperature on the ocean bottom was simulated with the assembled recorder package in a cold room $\left(\sim 0^{\circ} \mathrm{C}\right)$. The tool was connected to the recorder package through a simulated electromechanical cable. Each tape recorder was allowed to start after a delay. The time code oscillator was adjusted to minimize drift at $0^{\circ} \mathrm{C}$. This step was the first complete systems test. Fourth, all pressure seals on the tool and recorder package were tested to a pressure equivalent to $7 \mathrm{~km}$ of seawater.

In the fourth and final phase, the system was installed in shallow water $(3 \mathrm{~m})$. A 20 -foot vertical section of a 4inch drill pipe was sunk into the mud of Borrow Pit, Keehi Lagoon (on the south shore of Oahu, Hawaii). The tool was lowered into the drill pipe and the recorder package (connected to the tool with simulated cable) placed on the bottom for five days. Several Ocean-Bottom Seismometers (OBS) were deployed around the simulated hole and the signals were compared. Following this fourth phase the OSS system was deemed ready for installation in the deep ocean.

\section{INSTALLATION TECHNIQUE}

The OSS is designed to be emplaced in deep-sea drill holes through the drill string, without modification in the string or any special drilling equipment. The hole must be within $2^{\circ}$ of vertical and less than $35 \mathrm{~cm}$ in diameter, but otherwise can be whatever is available. For seismic reasons, it is desirable to emplace the tool in seismic basement rather than in sediments.

Four OSS systems were installed by the Glomar Challenger. Single-bit holes (without reentry cones) were drilled (Fig. 19). In three of the holes basement was reached. The system could be deployed from any drill rig on land or sea. The installation process is as follows:

1. When the drilling is complete, the drill bit is released and the normal hole-logging program is executed.

2. Following logging, the OSS tool is connected to the electromechanical cable that was used for the logging, tested, and lowered to the bottom of the hole with the logging winch. The tool is continuously monitored through slip rings. The geophones will quiet noticeably whenever the tool stops moving. When the tool reaches the bottom of the hole, it is raised a few meters and the pad is extended. The tool is tested for proper operation and the tilts measured to insure that the hole is close enough to vertical for proper operation of the geophones. With the tool functioning properly and the hole in good condition, the pad is retracted and the tool is lifted approximately $10 \mathrm{~m}$ in preparation for stripping the pipe from the electromechanical logging cable.

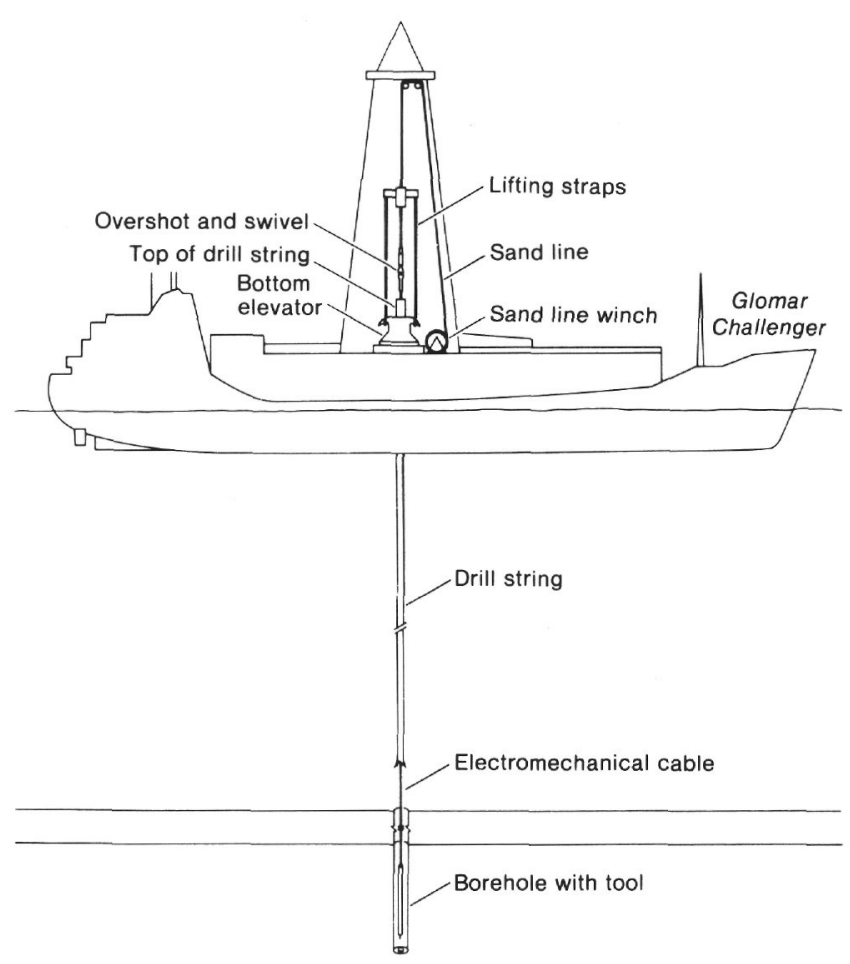

Figure 19. Diagram of Glomar Challenger during the pipe stripping process. Note: Scale is severely distorted. 
3. The electromechanical cable is clamped just above the rotary table and tension is transferred to the clamp. The cable is cut and a quick-release snap fitting is mated to the end of the cable. With the cable cut, it is no longer possible to monitor data from the tool (Fig. 20A).

4. An overshot and swivel are attached to the sand line and the overshot is connected to the snap fitting on the electromechanical cable. The tension of the cable is taken by the sand line and sand line winch. The cable clamp is removed (Fig. 20B). The swivel is necessary to prevent torques built up in the sand line from being transmitted down the cable to the tool, causing it to spin as the pipe is stripped.

5. Each stand of drill pipe $(32.5 \mathrm{~m})$ is removed in a repetitive six-step process. These steps are

(a) The stand is lifted with the elevator until the lower joint is even with the overshot (Fig. 20C).

(b) The second elevator is inserted below the joint. The drill string is lowered until it rests on the bottom elevator (Fig. 20D).

(c) The screw joint between pipe sections is then detached and the free stand is lifted by the upper elevator (Fig. 20E).

(d) A fork is placed in the notch of the snap fitting, and the sand line is lowered to transfer tension to the fork and the top of the drill string.
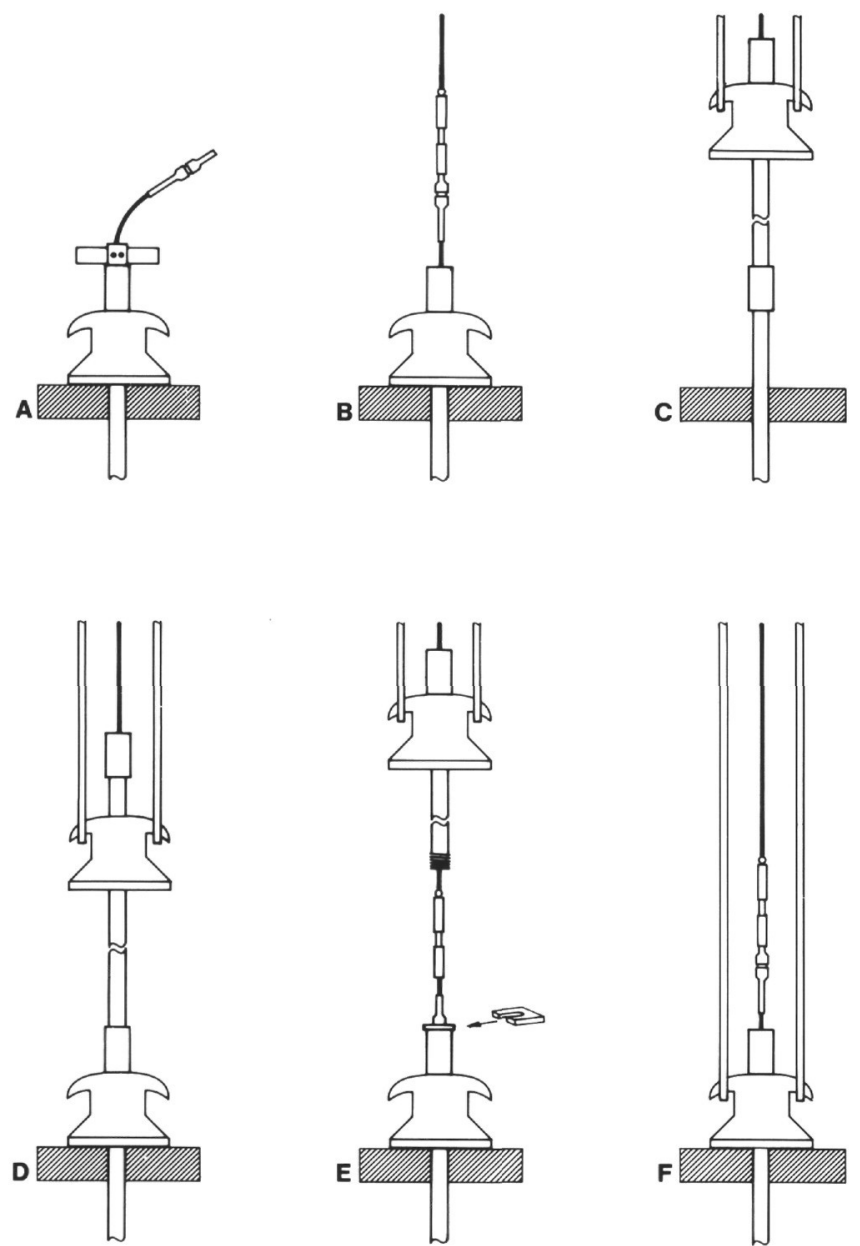

Figure 20. Pipe stripping process. See text for description. (e) The overshot is disconnected and the free stand is moved to the pipe rack. As the stand leaves the derrick, the sand line slides out of the upper end. The upper elevator is lowered and removed from the lifting straps.

(f) The lifting straps are attached to the lower elevator (Fig. 20F) and the process is repeated until the entire drill string is removed. The stripping process adds approximately 20 to $30 \%$ to the normal time required to recover the drill string.

6. When all the pipe is removed, the cable clamp is again attached to the cable below the snap fitting and the tension of logging cable is transferred to the clamp. A "torpedo" splice is installed to reattach the two halves of the cable. The splice construction technique is modified to increase longevity. Following the connection, signals from the tool can again be monitored and recorded. Tension is then taken by the spliced logging cable and the clamp is removed. The tool is lowered back to the bottom of the hole and the pad is extended. If the tilt meters indicate that the tool is not close enough to vertical for the proper operation of both horizontal geophones, the pad is retracted and reextended until a suitable position is achieved.

7. With the pad extended, approximately $200 \mathrm{~m}$ of cable are paid out and the tool is monitored for a few hours.

8. When the tool is considered properly installed and operating, the Challenger is allowed to drift off station while cable is paid out proportionately to the drift of the ship. Near the end of the cable an acoustic beacon is dropped and the ship is stabilized over it for seismic experiments. For OSS IV, these experiments included explosive and air gun lines conducted by a second ship (DeSteiger) which also deployed ocean-bottom seismometers.

9. When the seismic experiments are completed, the cable clamp is again installed, the cable cut, and a cablehead attached.

10. The electromechanical cable is keelhauled from the moon pool to the side of the Challenger and is hauled on deck.

11. The cable is attached to the assembled recorder package and data are monitored for at least $1 \mathrm{hr}$. to insure that the tool and recorder package are operating properly. The recovery rope, about $150 \%$ of the water depth in length, stored on a spool, is threaded around the tensioner and passed through a chocked hawser hole. The end of the recovery rope is attached to the recorder package. A crane lifts the recorder package over the side of the ship and lowers it until it is transferred to the recovery rope (Fig. 21).

12. The Challenger again is allowed to drift slowly while paying out the recovery rope. About a thousand pounds of tension is maintained to pull the cable and rope as far as possible.

13. At the end of the recovery rope, the recovery buoy is attached, lifted over the side with the crane, and cut free after further drifting. The recovery buoy transponders are interrogated and located when they settle on the ocean bottom, and they are commanded not to transmit. The Challenger is now free to proceed to the next task. 


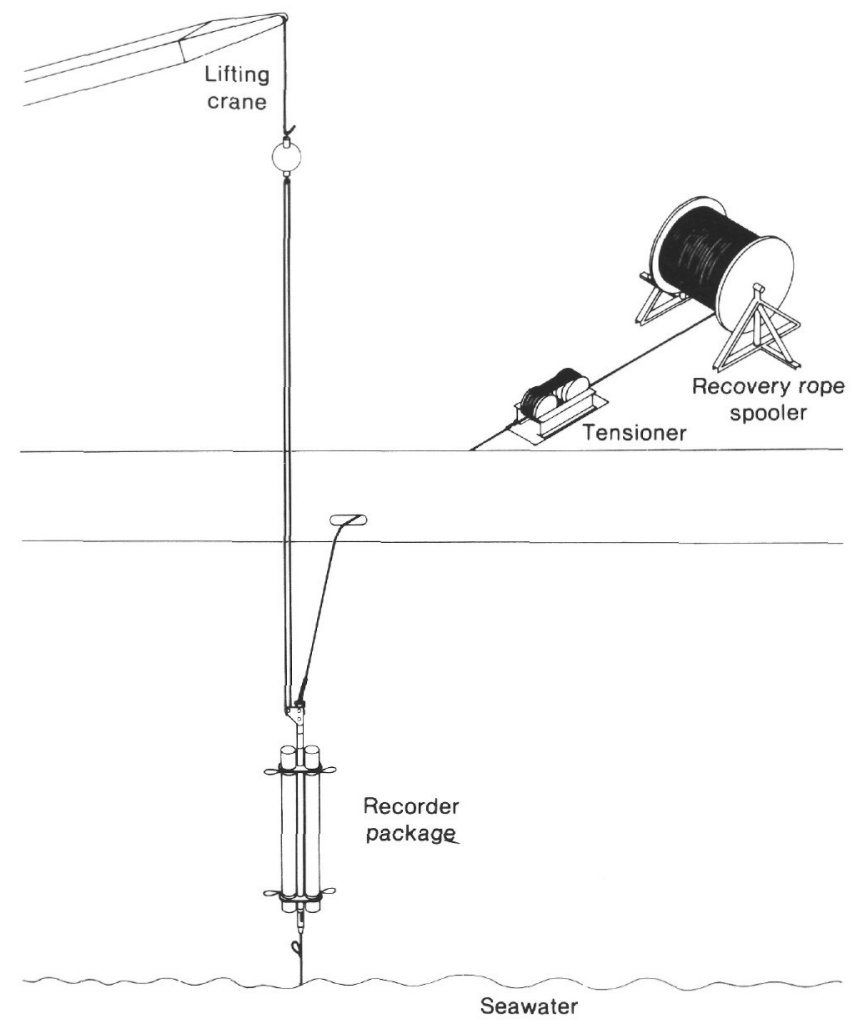

Figure 21. Installation of recorder package from the Glomar Challenger.

\section{RECORDER PACKAGE SERVICING}

The OSS may be serviced any time after deployment. The maximum recording time of the OSS IV, as presently installed, is 66 days. The recorder package may be serviced repeatedly (i.e., batteries and data tapes replaced) as long as the tool functions properly. Any midsized research ship ( $>50 \mathrm{~m})$ may be used. As already noted, three methods for recovering the recorder package have been planned: (1) normal recovery, in which the anchor is acoustically released; (2) first backup method-grappling for the recovery rope, (3) second backup method-grappling for the logging cable.

The recovery equipment is shown as installed on the deck of the Kana Keoki in Figure 22. All of the equipment can be transported in standard airline containers. A normal recovery proceeds as follows:

A. The recovery buoy, on the ocean bottom, is located with its acoustical transponders, and navigation transponders are dropped to help hold position. The recovery ship then is positioned above the recovery buoy.

B. Near sunrise, one release is acoustically commanded to release the expendable anchor. If this release fails, the second release is commanded to release. If the second release also fails, a backup recovery method must be used.

C. When the anchor is released (usually several minutes after command) the recovery buoy and the recovery rope begin to ascend. The ascent of the anchor buoy may be monitored with the transponders. Since the release is commanded in the morning, the recovery rope is usually sighted first before the transponders reach the surface.

D. The recovery buoy is brought aboard the ship and the recovery rope passed over the stern roller, through the tensiometer and counter, around the traction winch to the line puller, and into the storage hold.

E. The recovery rope is hauled in until the recorder package reaches the stern of the ship. This operation requires about $8 \mathrm{hr}$. in $5 \mathrm{~km}$ of water.

F. At this point, the tension of the system is taken by the ship's main winch wire. The winch's cable passes through the block on the stern A-frame and is attached to the coupler of the recorder package. The recorder package, with the electromechanical cable attached, is raised to the top of the A-frame, and a hook chained to the ship is attached to one of the preformed cable grips on the cable. The winch wire is lowered and tension is transferred to the hook through the electromechanical cable.

G. The recorder package is then lowered to the deck and disconnected from the cable. The cable is connected to the OSS test box and the tool is then tested for proper operation.

H. If the tool is operating properly, experiments are conducted using the high data rate mode and real time recording. After these are completed, a recording package with new battery and tape is attached to the cable, and the system is reinstalled. The anchor buoy transponding releases are refurbished and a new anchor is attached.

If the tool is not working properly, the electromechanical cable is passed around the traction winch and hauled in. This method has been attempted twice (OSS I and II) and the tool successfully recovered from the hole once (OSS I).

If the anchor buoy does not release the anchor, a weighted grapple is connected to the main ship's winch to grapple for the recovery rope. The grapple is lowered to within $10 \mathrm{~m}$ of the ocean bottom while the ship sails slowly across the rope near the anchor buoy. The recovery rope can be cut by the winch wire or grapple with no noticeable change in wire tension. If the rope is cut, the free ends of the recovery rope ascend toward the surface. The longer piece connects to the recorder package and is recovered, but the recovery buoy is lost. In the event that the recovery rope is not cut during the ship's first pass, the ship crosses again nearer the borehole and another attempt is made. This procedure is repeated until the recovery rope has been cut. This technique has achieved one successful recovery.

The second "desperation" backup recovery method, which requires dragging the grapple across the ocean bottom to catch the electromechanical cable, has not yet been used.

\section{SIGNAL PROCESSING}

Several types of data have been recovered from OSS IV. Analog records include passive seismic sources such as earthquakes (teleseismic and local) (Fig. 23A), active seismic sources such as refraction seismic shooting (explosives and air cannons) (Fig. 23B) and nuclear tests (Fig. 23C). Wideband noise levels have been plotted (Fig. 


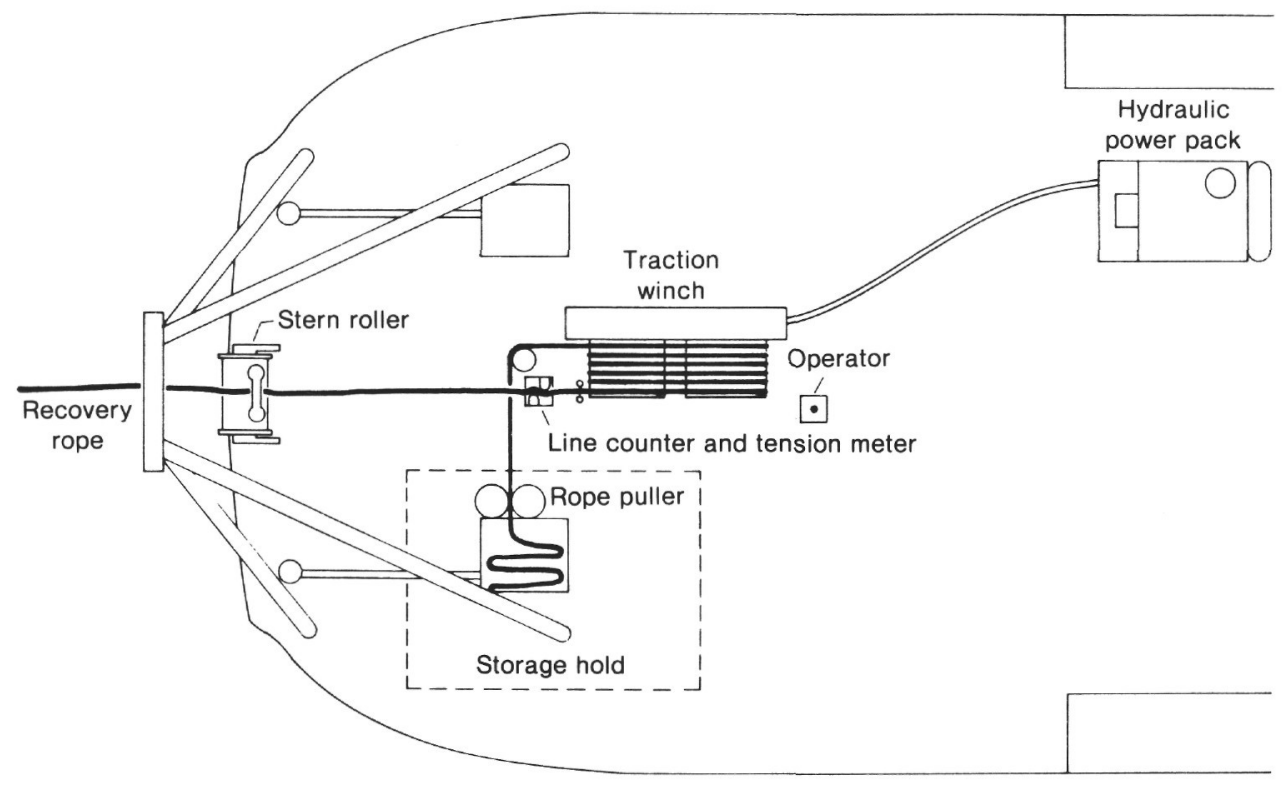

Figure 22. OSS recovery equipment installed aboard the stern of the Kana Keoki.

24) for the entire 65-day recording period, as have digital records of slowly varying parameters such as temperature and tilt (Fig. 25).

\section{Analog Cassette Tape Processing}

The analog signal processing proceeds through several steps. The tape cassette is played back twice; first, to recover the geophone amplifier gain levels and other digital words corresponding to slowly varying geophysical parameters imbedded in the time code, and second, to copy the recording to $1 / 2$-inch magnetic tape to permit mechanical slowdown for digitizing the seismic data. The seismic data are processed to remove time-code drift and then further processed to correct for gain changes where absolute amplitude is important. The digitized signal amplitudes are referenced to absolute levels by comparison to the time-code amplitude and correcting for the AGC gain levels.

Time code drift is normally corrected by comparing the launch and recovery time codes to universal time. A constant rate of time drift (or frequency offset) is assumed between the two "fixed" points. This practice has been found to be adequate for HIG OBS systems using the same type of oscillator as the OSS. Unfortunately, during the recovery of the OSS IV in May 1983, time code was not checked until several days after recovery, and by then the recorder package had warmed to room temperature. At that time it had acquired $40 \mathrm{~s}$ of offset since emplacement 9 months earlier. It is difficult to determine how much of this drift occurred on the ocean floor and how much on the recovery ship, so these data are not suitable for calculation of clock drift. The times of first arrivals from several seismic events located by the Worldwide Standardized Seismic Network (WWSSN) and recorded during this deployment provided timing constraints sufficient to determine an assumed constant drift of $+0.17 \mathrm{~s}$ per day.
The digitizing rate is locked to the $10-\mathrm{Hz}$ time-code carrier to reduce the effect of tape speed variations ("wow" and "flutter") in the final digital time series. These variations during recording are about $1 \%$ or less of the digital sampling interval, and errors attributable to them are typically about $\pm 5 \mathrm{~ms}$.

\section{Wideband Noise}

Wideband noise levels have been analyzed by using an HP3582A Spectrum Analyzer controlled by a TRS80 Model III microcomputer. While each cassette was played, the analyzer obtained spectral estimates for small sections of the analog signals about once every $30 \mathrm{~min}$. (ocean-bottom time). A total of 128 spectral estimates were obtained for each of the horizontal geophone channels. The passband used provided estimates of signal amplitude at frequencies from DC to the Nyquist frequencies of the data coming from the tool $(25 \mathrm{~Hz})$. Spectral estimates transmitted over a general purpose interface bus (GPIB) were coded by the TRS- 80 into RS-232 format, relayed to a PDP-11 microcomputer for buffer storage, and written on a 9-track tape. Plots made from averaged third-octave frequency bands reveal excellent correlation between the passage of weather systems and seismic noise levels (Fig. 24; see also Duennebier, Harris, and Cessaro, this volume).

\section{Earthquake Processing}

Processing OSS data for earthquakes is the same as processing HIG OBS data. The analog seismic data are connected to the input of a hardware event detector (Cessaro, 1983) and continuously digitized and stored in computer memory. On a signal from the event detector, the computer transfers the contents of an internal storage buffer to 9-track digital tape. The use of a storage buffer allows us to capture noise occurring before the event detection criteria are met. 
A
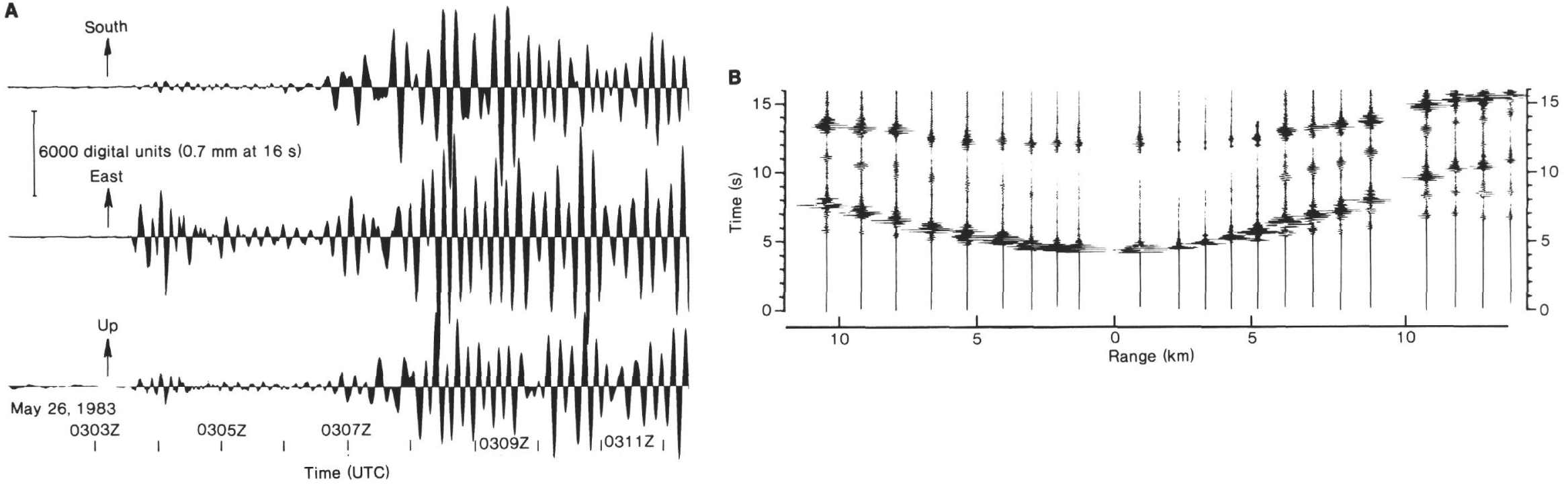

South

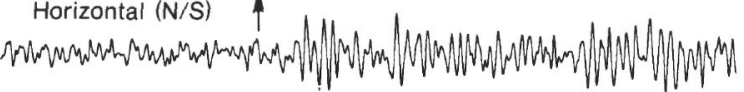

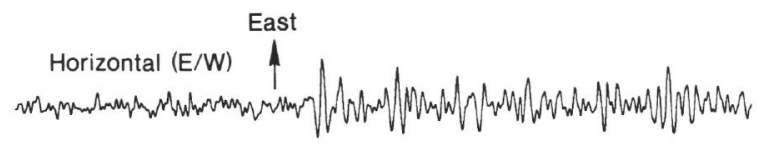

] $90 \mathrm{~nm} / \mathrm{s}$

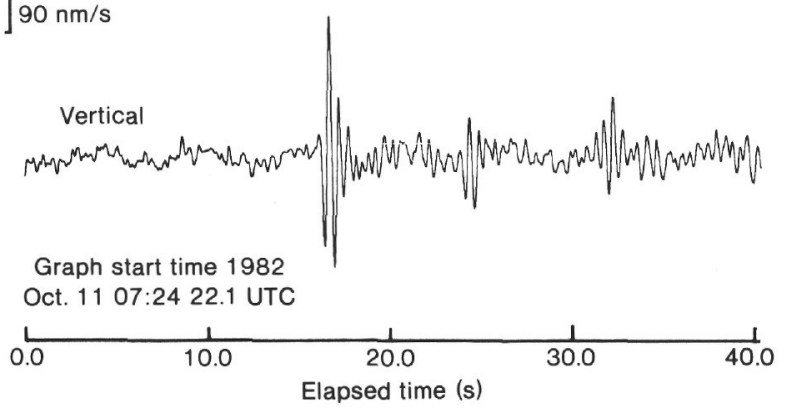

Figure 23. A. Example of teleseismic event as recorded by OSS IV: Japan earthquake of May $26,1983\left(43^{\circ} 55^{\prime} \mathrm{N}, 155^{\circ} 48^{\prime} \mathrm{E}\right)$. B. An OSS IV refraction line; uncorrected for navigation. The explosives sources were small charges (1.5 lb) dropped from a U.S. Navy P-3 Orion aircraft. C. Example of recording a nuclear explosion; Novaya Zemlya, 5.6 M $($ Oct. 11,1982$)$. 


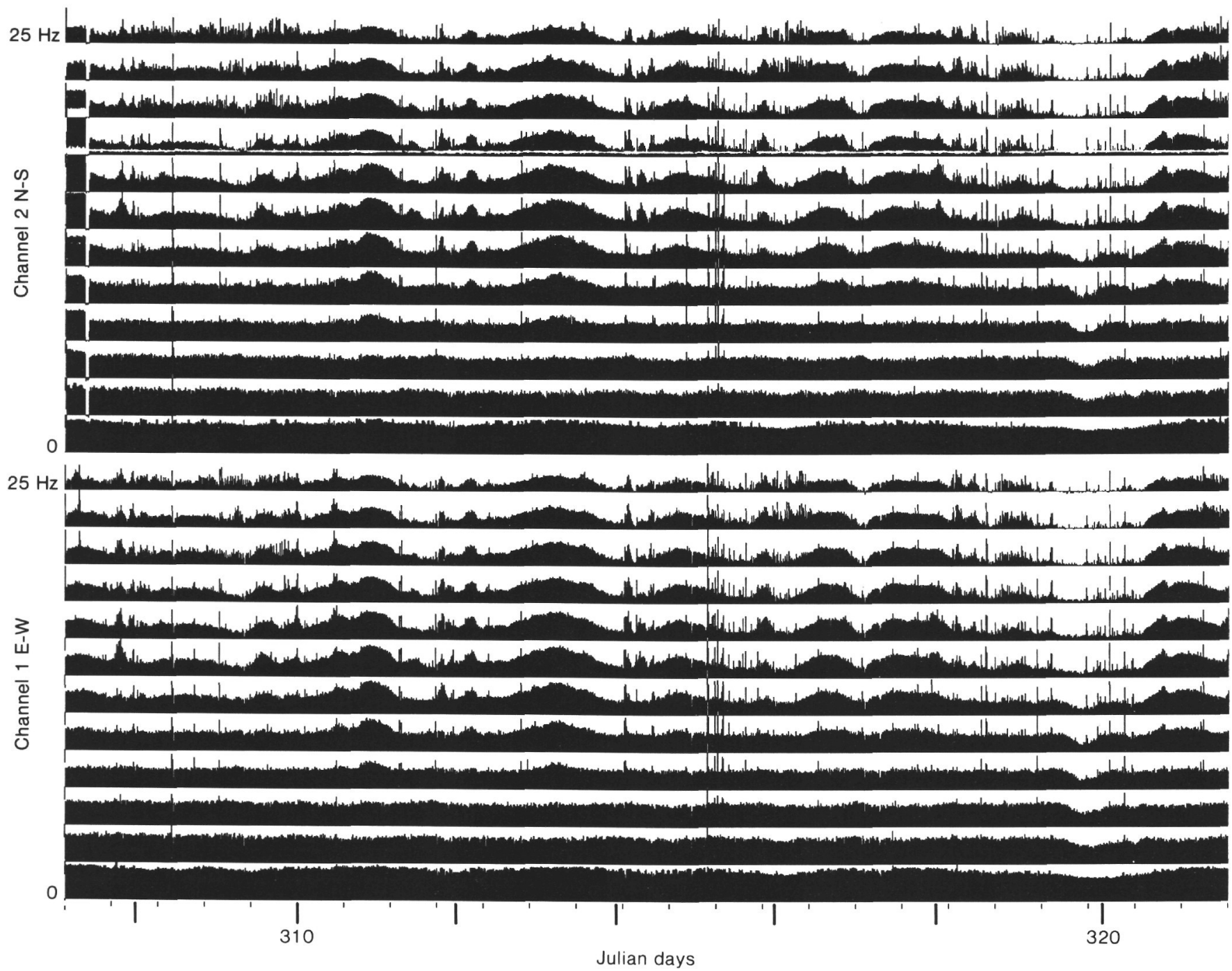

Figure 24. Example of data from long-term wideband noise level in third octave bands from the two horizontal geophone channels.

The event detector, although designed for detecting seismic events recovered from OBS systems, works reasonably well for the OSS. One problem that has been identified while recovering data for the OSS is that the gain steps in the OSS are $12 \mathrm{~dB}$ whereas in the OBS they are only $6 \mathrm{~dB}$. The event detector often triggers when the gain is increased and is being redesigned to include the gain levels encoded in the time code as part of its detection criteria.

\section{FUTURE PLANS AND MODIFICATIONS}

Although the OSS IV installation is successful, several problems have been identified and improvements can be made to the system. The most troublesome problem is a vertical geophone DC offset. The vertical geophone stack is in the extended pad. Signals are connected to the upper pressure case through two insulated conductors exposed to ocean water and ambient pressure. A small leak in the insulation or in one of the connectors could cause a galvanic effect and produce the DC offset. This problem could be corrected by extending the upper pressure case and placing the vertical geophones inside it or by placing a preamplifier in the pad to increase the level of the geophone output and lower its impedance before being exposed to seawater. This method, however, would require a supply of power to the pad.

The recording time could be increased by a factor of 2 by adding two more pressure cases with additional tape recorders and batteries to the present recorder package. This addition would increase the long-term recording to 132 days with minimal impact upon the cost of the program. The present recorder package could be replaced by a digital recording system or even a buoy for continuous data transmission to a satellite. Both of these options would be expensive and more difficult to make as reliable as the present system.

\section{ACKNOWLEDGMENTS}

The people responsible in some part for the overwhelming success of this experiment are too numerous to mention, but several individuals and groups were indispensable to its success. Charles Helsley, the director of HIG, supplied the initial support and financial backing to get the project started. The first two emplacements were funded by the National Science Foundation. All funding since 1979 has been supplied by the Office of Naval Research, and we greatly appreciate their 
D. A. BYRNE, D. HARRIS, F. K. DUENNEBIER, R. CESSARO

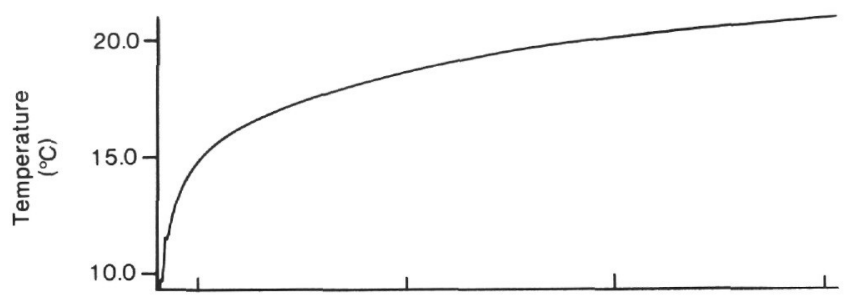

confidence and support. Technical support and important ideas were supplied by the technical and scientific staff of the Deep Sea Drilling Project. This system was designed and built by the staff of the HIG Engineering Support Facility, with special thanks to Grant Blackinton, David Barrett, Bert Mattes, R. Mitiguy, and R. Richards for their initial designs and continuing support. We thank George Sutton for reviewing the manuscript. This is Hawaii Institute of Geophysics contribution no. 1665 .

\section{REFERENCES}
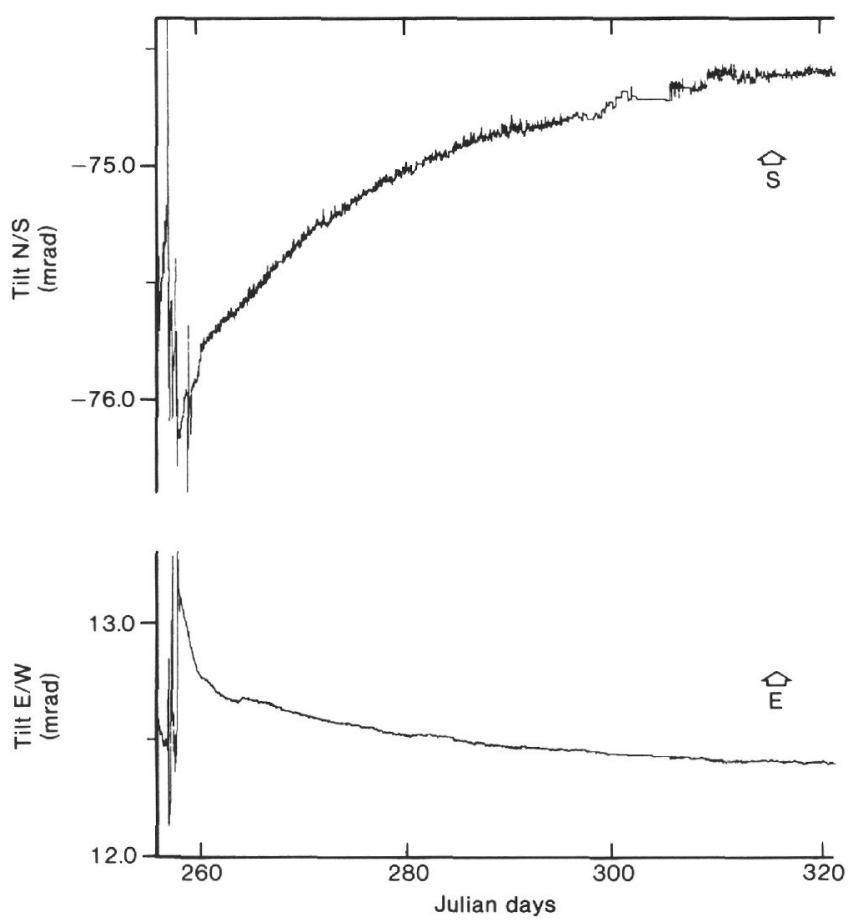

Aubouin, J., von Huene, R., et al., 1979. Site 494: Middle America Trench Slope. Init. Repts. DSDP, 67: Washington (U.S. Govt. Printing Office).

Cessaro, R. K., 1983. Transform seismicity of the intersection of the Mid-Atlantic Ridge and the Oceanographer Fracture Zone [M.S. thesis]. University of Hawaii, Honolulu.

Duennebier, F., and Blackinton, J. G., 1980. A man-made hot spring on the ocean floor. Nature, 284:338-340.

, 1983. The ocean subbottom seismometer. In Geyer, R. A. (Ed.), Handbook of Geophysical Exploration at Sea: Boca Raton, Florida (CRC Press), pp. 317-332.

Duennebier, F. K., Sutton, G. H., Harris, D., and Byrne, D. A., 1984. A simple shaker table for seismometer calibration. Marine Geophys. Res., 6:311-328.

Lewis, B. T. R., Robinson, P. T., et al., 1979. Site 482. Init. Repts. DSDP, 65: Washington (U.S. Govt. Printing Office).

Date of Initial Receipt: 11 June 1984

Date of Acceptance: 22 November 1984

Figure 25. Temperature and tilt data for the entire 65-day recording period. 
APPENDIX

OSS Specifications

A. Installation requirements

Ship

Total station time for installation after drilling

HIG personnel on drill ship

B. Service requirements

Minimum ship length

Maximum time between servicing

Acoustical release recovery

Grapple recovery

Number of possible services

Recovery ship station time

Traction winch (for recovery)

Weight (winch only)

Base dimension

Grooves

Line sizes

Manufacturer

Power source

Drive

C. Borehole package (tool)

General

Manufacturer (mechanical section)

Modified by

Outside diameter

Overall length

Weight (with geophones and electronics in case)

Max. depth

Mechanical

Upper pressure case

Inside diameter

Inside length

Pad

Inside diameter

Inside length

Electrical

Sensors

Geophones

Tilt sensors

Temperature sensor

Digitizer

Number of channels

Sample rate

Tier 1

Tier 2

Tier 3

Tier 4

Dynamic Range

D. Electromechanical cable

Manufacturer

Normal diameter

Weight

In air

In fresh water

Breaking strength, ends fixed (min. calc.)

Minimum sheared/drive diameter

Armor

Inner

Outer

Conductors

Number

Inner (1 each)

Outer (6 each)

Insulation

Characteristic impedance

Resistance (total $10 \mathrm{~km}$, one wire)

Capacitance (total $10 \mathrm{~km}$ )
Glomar Challenger (or equivalent) $72 \mathrm{hr}$. (est.)

$>50 \mathrm{~m}$

2 yr.

Unlimited

Unlimited

72 hr. (est.)

$2000 \mathrm{~kg}$

$1.5 \mathrm{~m} \times 2.5 \mathrm{~m}$

$3 \mathrm{~cm}$ and $1 \mathrm{~cm}$

University of Hawaii

$45 \mathrm{HP}$

Hydraulic

Gearhart Industries

HIG

$7 \mathrm{~cm}$

$2.5 \mathrm{~m}$

$41 \mathrm{~kg}$

$6 \mathrm{~km}$

$6 \mathrm{~cm}$

$87 \mathrm{~cm}$

$4.8 \mathrm{~cm}$

$58 \mathrm{~cm}$

Geospace Model HS-1 4.5 Hz,

$5 \mathrm{kohm}$ coil, 4 horizontal and 9 vertical

Fredericks Model 7660

Analog Devices AD590

16

50 or 100 samples/s

12.5 or $25 \mathrm{samples} / \mathrm{s}$

3.125 or 6.25 samples/s

1.28 or $0.64 \mathrm{~s} / \mathrm{sample}$

$138 \mathrm{~dB}$

Rochester

$1.2 \mathrm{~cm}$

$346 \mathrm{lb} / 10^{3} \mathrm{ft}$.

$289 \mathrm{lb} / 10^{3} \mathrm{ft}$.

$7,500 \mathrm{~kg}$

$61 \mathrm{~cm}$

RHL (right-hand lay)

LHL (left-hand lay)

7

\#20 AWG $\left(6 / .0142^{\prime \prime}\right)$ copper \#20 (AWG (7/.0126' ') copper Ethylene propylene copolymer $34 \mathrm{ohm}$

$164 \mathrm{ohm}$

$2.4 \mu \mathrm{F}$ 
E. Recorder package Mechanical

Weight in air (empty) $140 \mathrm{~kg}$

(loaded) $220 \mathrm{~kg}$

Overall dimensions

$220 \mathrm{~kg}$

Pressure Cases

Length

Outside diameter

Inside diameter

Material

Type of seal

Maximum depth

Corrosion protection

Swivel

Assembly rod

Length

Diameter

Material

Electronics

Batteries

Printed circuit boards

Tape recorders

Total record time (1 day overlap)

Time code

Format

Carrier

F. Recovery rope

Material

Nominal outside diameter

Construction

Breaking strength

Length

G. Anchor buoy and anchor

Height

Anchor buoy only

With anchor assembly

Flotation

Type

Number

Manufacturer

Diameter

Mass

Buoyancy

Service depth

Anchors

Main anchor

Type

Material

Weight (in air)

Drag anchor

Type

Material

Size

Anchor release system

Actuator

Separator

$190 \mathrm{~cm}$

$18 \mathrm{~cm}$

$14.5 \mathrm{~cm}$

7075-T6 aluminum

Redundant " $O$ " ring radial and corner (each end cap)

$10 \mathrm{~km}$

Sprayed zinc coating

Miller, type 3, Model D, 5-ton working load

$220 \mathrm{~cm}$

$6 \mathrm{~cm}$

6061-T6 aluminum

198 alkaline " $D$ " cells

10

5 at 14 days each 66 days

Modified IRIG-H

$10 \mathrm{~Hz}$

Polypropylene

$3.2 \mathrm{~cm}$

8-strand plaited

$10,000 \mathrm{~kg}$

Greater than $1.5 \times$ the water depth

$1.7 \mathrm{~m}$

$57 \mathrm{~m}$

Glass spheres

2

Corning 690496

$40 \mathrm{~cm}$

$17 \mathrm{~kg}$ (each)

$220 \mathrm{~N}$ (each)

$6 \mathrm{~km}$

Cast cylinder

Lead

$900 \mathrm{~kg}$

Danforth

Steel

28 in., 12-H

Either of two Sonatech Model 410 acoustic transponding releases

Either of two dissolving wire release mechanisms 